\title{
Variables biológicas y culturales de la sexualidad en la percepción de los universitarios
}

\author{
Ramón León \& Manuel Fernández \\ Universidad de Lima \\ Lima, Perú
}

El propósito de la presente investigación es averiguar el valor otorgado por los adolescentes y jóvenes a una serie de variables biológicas y sociales en sus actitudes y conductas sexuales. Se consideraron las siguientes variables: la figura materna, la figura paterna, la religión, el temor al qué dirán, el impulso sexual, la educación sexual recibida en el colegio, las amistades, la curiosidad sexual, el peligro del sida, el autocontrol y la ocasión. Asimismo, se indagó acerca de la valoración que se da al hombre o mujer que haya tenido relaciones sexuales antes del matrimonio, así como los estereotipos de la sexualidad del costeño, del serrano y del selvático. Los resultados permiten reconocer el valor diferencial que conceden hombres y mujeres de la muestra a la importancia de la dimensión sexual en sus respectivas vidas.

variables biológicas de la sexualidad / variables culturales de la sexualidad / universitarios

\section{Biological and cultural variable of sexuality in the perception of college students}

The purpose of this research is to determine the value given by adolescents and young adults to a set of biological and social variables of their behaviors and attitudes towards sexuality. The following variables were considered: mother's and father's images, religion, fear of "what are they going to say", sexual impulse, sexual education received in school, friends, sexual curiosity, risk of AIDS, self-control, and response to particular situations. The set of variables included the value given to men or women who had had sexual relations before marriage, sexual stereotypes of people of the Peruvian coast, the Andes and the Amazon. The results showed that men and women give different value to the sexual dimension in their lives.

biological variables of sexuality / cultural variables of sexuality / college students 
Aunque Havelock Ellis debe ser mencionado como uno de los pioneros en el estudio del comportamiento sexual, es recién con Sigmund Freud que se concede a la sexualidad fuerza preminente en el desarrollo de la personalidad y en la dinámica psicológica del individuo. Podemos afirmar que a partir de él, se entendió que "la conducta sexual humana cumple, en el comportamiento humano globalmente considerado, una serie de funciones distintas: reproductoras, hedonísticas, relacionales y de tipo egointegrativo" (Llor et al., 1998, p. 80). Es decir, la sexualidad no es sólo un impulso biológico sino también un constructo social (Giddens, 1998).

Desde los trabajos del padre del psicoanálisis mucho se ha ganado en información acerca de la conducta sexual. Un papel de importancia ha sido el de Masters \& Johnson (Routh, 1998). En la actualidad, para citar a Kaplan et al. (1996), se puede concluir que la conducta sexual no puede ser reducida sólo a la categoría de instinto, sino que "es muy variada y viene determinada por complejas interacciones entre diferentes factores", siendo "afectada por la relación que una persona tiene con los demás, por las circunstancias de su vida, y por la cultura en que se vive" (p. 669).

Esta información ha traído como consecuencia cambios en las actitudes de la sociedad, tornándolas más permisivas frente a temas otrora cargados de conflictividad (Jacoby y Williams,
1985). Tal es el caso del comportamiento homosexual, frente al cual se registra una apertura de criterio inimaginable hasta hace sólo unos 30 años.

Giddens (1997) afirma que:

... al crearse los nuevos nexos entre sexualidad e intimidad, la sexualidad se separó de la procreación mucho más plenamente que antes. La sexualidad quedó doblemente constituida como medio de realización propia y como instrumento primordial y expresión de la intimidad. Al llegar aquí, la sexualidad pierde sus vínculos extrínsecos con tradiciones y éticas más amplias, así como con la sucesión de las generaciones. La sexualidad es, o más bien llega a ser, un punto de referencia fundamental para la "experiencia", palabra que adquiere un especial significado en relación con la vida sexual (1997, p. 209).

Esa actitud más liberal con respecto al sexo ha dado lugar también a una redoblada actividad investigatoria sobre el tema. Saber qué fuerzas psicológicas, sociológicas, antropológicas y económicas influyen en la conducta sexual no sólo permite ahondar en el conocimiento de la naturaleza humana; tiene también importancia práctica, especialmente en el desarrollo de los programas de educación sexual.

Lamentablemente, la información que poseemos es muy escasa todavía, a pesar de todos los progresos registrados. No se trata sólo de acumular conocimientos con fines exclusivamente científicos. Mientras que a fines de la década de los setenta la actividad sexual parecía haber alcanzado un elevado grado de libertad, expresada a través 
del amor libre, los métodos anticonceptivos, la presencia de efectivos medios para combatir las enfermedades venéreas, la aparición del sida introdujo una dimensión de riesgo hasta ese momento inimaginada.

Como se sabe, no existe aún cura para el sida, de modo tal que la mayoría de las sociedades ha apostado a técnicas educativas masivas y a una agresiva campaña de información, con el propósito de prevenir la difusión de esta enfermedad (Linville et al., 1993).

Sin embargo, hoy se sabe que la información por sí sola no modifica comportamientos riesgosos (Becker y Joseph, 1988; Fernández, 1998; Leventhal \& Clearly, 1980). Uno de los resultados más dramáticos después de más de una década de campañas de prevención del sida, es que informar acerca del riesgo de contraerlo no ha impedido que éste siga difundiéndose. Esto destaca la importancia de otras variables que los programas de prevención del sida no están considerando con el cuidado con el que deberían hacerlo (Van Landingham et al., 1997).

El desconocimiento acerca de los factores que influyen en la conducta sexual es, por supuesto, grande en una sociedad como la peruana, en la cual la discusión acerca de temas sexuales fue por mucho tiempo un asunto virtualmente prohibido. Afortunadamente, en los últimos años esta situación ha cambiado: hoy sabemos más acerca de lo que piensan los adolescentes peruanos en cuanto a sexualidad en general (Loli, sin fecha; Soto Cáceres, 1972; Fernández, 1989; León \& Cossío de Preciado, 1993; La Rosa, 1997; Ponce \& La Rosa, 1995; Alarcón \& González, 1994a, 1994b); sobre su comportamiento en el uso de técnicas anticonceptivas (Fernández, 1998); e inclusive tenemos alguna información sobre las fantasías sexuales de ellos (León \& Puga Vásquez, 1997).

El presente trabajo explora cuáles son las variables que los adolescentes y jóvenes consideran que tienen importancia en la conducta y actitudes sexuales de ellos.

Puesto que los programas de educación sexual se dirigen precisamente a adolescentes y jóvenes, es apropiado preguntarles a ellos mismos cuáles creen que son las variables sociales y naturales que, según su parecer, determinan las actitudes y conductas sexuales.

Esto permitirá cubrir (aunque sea parcialmente) uno de los grandes vacíos en materia de investigación de género -anotado por Ruiz Bravo (1996)-, el del conocimiento de la realidad de los jóvenes, respondiendo así a algunas de las preguntas centrales: por ejemplo, cómo es que ven ellos las relaciones entre hombres y mujeres, o cuáles son sus discursos, representaciones y expectativas de género.

De otro lado, creemos que la información obtenida puede arrojar luces acerca de algunas variables poco exploradas en el terreno sexual, y orientar a 
quienes diseñan programas de educación sexual en el énfasis de aspectos que tal vez no hubieran sido tomados en cuenta.

Qué piensan los adolescentes y los jóvenes acerca del sexo, del futuro, de la familia, de la vida: éstas son preguntas que un adulto difícilmente podrá responder. Es necesario solicitarles a ellos mismos una respuesta, a fin de entender el mundo en el cual ellos viven. La dimensión de la sexualidad incluida.

\section{FACTORES CONDICIONANTES DE LA SEXUALIDAD}

Desde la antigüedad el comportamiento sexual ha sido objeto de control y restricción. Paradigmática es la posición del cristianismo que, especialmente a partir de san Pablo, desarrolló una línea dura en materia de sexualidad (Goffi, 1983). La sexualidad prematrimonial, la sexualidad que no conduce a la procreación, la homosexualidad y otras variantes del comportamiento sexual, como el onanismo: todas ellas fueron condenadas por la doctrina cristiana, sancionándolas con severas penas en este mundo así como en el más allá.

El desconocimiento y la restricción perduraron hasta aproximadamente fines del siglo XIX. Mérito indiscutible de Freud y de Ellis es haber comenzado a descorrer el velo que se cernía sobre este dominio de la conducta humana. Mientras que Ellis llevó a cabo lo que hoy llamaríamos investigación an- tropológica en materia del sexo (Howell \& Osborn, 1984), Freud, utilizando su experiencia clínica, formuló una teoría en la cual el sexo desempeña el rol central en la personalidad (Nitzschke, 1982). Uno y otro destacaron la importancia de poderosos componentes biológicos en la sexualidad humana.

La vinculación de la sexualidad a la perpetuación de la especie determinó el rechazo primero y la condena después de todas aquellas conductas sexuales que no conducían a ella, a las que se suelen llamar aún hoy con cierta frecuencia "conductas desviadas". Probablemente un gran interés por establecer las fuerzas que gobiernan la sexualidad humana provino de la necesidad de entender el comportamiento sexual no vinculado a la perpetuación de la especie (Rivera-Mosquera \& Dowd, 1999).

Fue Kinsey quien contribuyó decisivamente a tener una idea realista de la conducta sexual del hombre de hoy (Kinsey et al., 1948, 1953). Mérito central de Kinsey es haber roto con el tabú de los temas sexuales como materia de investigación (Schaffer, 1981). De allí en adelante los trabajos sobre este tema se han multiplicado, investigándose los aspectos más variados desde las perspectivas más diversas.

Quedan, sin embargo, algunas interrogantes que van más allá de la frecuencia y de la intensidad de la vida sexual de los individuos, dos de los temas más investigados: ¿Es la sexualidad del 
hombre más intensa que la de la mujer, como se suele pensar?; y, ¿cuán importante consideran las personas que es la sexualidad en sus vidas?

Se trata de interrogantes que desbordan lo estrictamente psicológico y lo sexológico para ingresar en el dominio antropológico y social. Son, por supuesto, preguntas recientes, inimaginables por ejemplo en el siglo pasado, que han surgido de poderosas corrientes sociales, pues es fácil reconocer en nuestros tiempos un marcado interés por lo sexual, en la televisión, en la política, en la cultura (Fagothey, 1992).

Por último, estas preguntas tienen connotaciones sociales de magnitud. Un rasgo central de las sociedades contemporáneas es el énfasis en la planificación familiar: el crecimiento más lento de la población es visto como una condición indispensable para el desarrollo de una sociedad más justa y más rica, que satisfaga las necesidades de realización personal de quienes la conforman. Obviamente, el menor crecimiento de la población supone una menor frecuencia de conducta sexual reproductiva, o relaciones sexuales con técnicas anticonceptivas, que es a lo que se encaminan las políticas demográficas (Wang et al., 1995).

Aparte de esto, desde comienzos de los años ochenta la sociedad ha enfrentado un nuevo e inesperado desafío. Nos estamos refiriendo al sida, cuya vinculación con la actividad sexual es evidente. Desde su aparición, y dada la ausencia de una vacuna o una cura, se han desarrollado muchos programas de prevención, los cuales orientan parte de su influencia al control de conductas sexuales de riesgo e insisten en lo que se suele llamar sexo seguro (Peterson \& Marín, 1988). En el mundo de hoy, cada vez más consciente de los riesgos que acompañan a la modernidad (Giddens, 1993), Susan Sontag observa que el sida ha despertado el miedo a la sexualidad, que "es el nuevo registro del universo de miedos en que vivimos hoy todos" (1996, p. 154).

A pesar de que la gente sabe hoy más acerca del sexo y es más consciente de los riesgos vinculados a una actividad sexual sin control, el sida continúa extendiéndose. En parte, debido a que la infección puede ser contraída no sólo a través de relaciones sexuales, como en el comienzo se supuso, sino también por personas que consumen drogas por vía intravenosa, sus parejas sexuales, sus hijos y pacientes hemofílicos (Fisher \& Fisher, 1993).

Pero la difusión del sida proviene, asimismo, de que los cambios de las conductas de riesgo han sido poco consistentes y más bien modestos (Fisher \& Fisher, 1993).

Una serie de condicionamientos de carácter psicológico es responsable de esto. La mayoría de las personas tiene un optimismo sostenido, por medio del cual cree que está por encima de riesgos y peligros (Giddens, 1993): se sobrevaloran las medidas de seguridad 
que se asumen y se subestiman las posibilidades reales de peligro (Van der Pligt et al., 1993). De otra parte, muchos varones se resisten al empleo de preservativos (Mays \& Cochran, 1988), arguyendo que se trata de una práctica que resta espontaneidad a la relación sexual. La dinámica interpersonal es, asimismo, decisiva (Miller et al., 1993). Por último, muchas mujeres contraen el sida vía sus maridos, que han tenido una relación extramatrimonial que los ha infectado.

Si la información no basta, resulta obvio que otros factores no estrictamente cognitivos desempeñan algún papel de significación en la conducta sexual. Esto ha sido reconocido desde siempre. Por ejemplo, en sociedades tradicionales el ejemplo de la madre es considerado decisivo para el comportamiento futuro de la hija, no sólo en el terreno sexual. Así, en la clase media peruana "la mujer es la reina del hogar y la encarnación de todos los valores asociados a la intimidad, el afecto y la lealtad hacia el grupo" (Fuller, 1993, p. 32).

Toda sociedad tiene algunas ideas implícitas acerca de las fuerzas que gobiernan la vida sexual, las que son transmitidas de una generación a otra. Explorarlas puede permitir reconocer variables de influencia en la conducta sexual, variables que no sólo son las del impulso y la curiosidad sexuales, que comienzan a manifestarse en la pubertad, sino que 'están en la atmósfera'.
Las teorías de Eysenck acerca de los vínculos entre dimensiones de personalidad (en especial, la dimensión introversión-extraversión) y el comportamiento sexual (Eysenck, 1978; Eysenck y Wilson, 1979; Wilson, 1997) destacan, por ejemplo, elementos genéticos, a los que cada día se presta más atención en el mundo de la medicina y de la psicología. Pero la "revolución sexual" a la cual hemos aludido al comienzo de nuestro trabajo, tiene poco que ver con factores genéticos; ella resulta más bien de condicionantes sociales que se perfilan con claridad como fuerzas a tomar en consideración a la hora de entender el comportamiento sexual humano.

Nos interesó en el presente estudio averiguar qué valor atribuían los adolescentes y jóvenes a una serie de aspectos biológicos y sociales en sus actitudes y conductas sexuales. Analizar esto permitirá obtener información acerca del modo en que los encuestados entienden, explican y probablemente buscan que regular su conducta sexual. Esa información posibilita, a su vez, entrever concepciones ideológicas (como, por ejemplo, el machismo), temores, expectativas y estereotipos de gran influencia en el modo en que la persona asume y despliega su sexualidad.

Para tal efecto consideramos las siguientes variables: la figura materna, la figura paterna, la religión, el temor al qué dirán, el impulso sexual, la educa- 
ción sexual recibida en el colegio, las amistades, la curiosidad sexual, el peligro del sida, el autocontrol y la ocasión.

Además, nos interesó conocer la percepción de los encuestados acerca del modo en que la sociedad peruana valora que el hombre/la mujer hayan tenido relaciones sexuales antes del matrimonio, así como los estereotipos de la sexualidad del costeño, del andino y del selvático.

\section{La figura materna}

La madre es reconocida en todas las sociedades civilizadas como la responsable de criar al niño, educarlo y transmitirle normas y valores de la sociedad (Berenstein, 1995). A pesar de los cambios ocurridos en la situación social de la mujer, la sinonimia mujer-madre conserva todavía mucho de la vigencia que tuvo en el pasado, cuando la identidad femenina era definida por la maternidad. En efecto: todavía en los años setenta, anota Kogan (1996, p. 30), en el Perú "la identidad femenina parecía construirse a partir de la maternidad y conyugalidad, quedando en un segundo plano -muy lejano-el rol profesional".

En la ideología machista, la madre es idealizada, vista como un ser abnegado y asexuado que a través del ejemplo se constituye en el desideratum de mujer para sus hijos y en modelo a seguir por sus hijas en materia de comportamiento sexual. Evelyn P. Stevens (1977) ha acuñado el término de marianismo, o sea "el culto a la superioridad espiritual femenina, que enseña que las mujeres son semidivinas, superiores moralmente y más fuertes espiritualmente que los hombres" (p. 123). Si bien es verdad que se le reconoce derecho a la sexualidad, ésta queda vinculada a la conyugalidad (Fuller, 1993).

En la familia peruana promedio la madre sigue ocupando un lugar capital. Ella es fuente de afecto incondicional, de consejo desinteresado, depositaria de las inquietudes, expectativas y angustias de sus hijos. En el terreno de la educación sexual su misión es la de transmitir sólidos valores a sus hijas y orientar en el proceso de desarrollo de la masculinidad a sus hijos varones. Ternura, sensibilidad y delicadeza, valores siempre atribuidos a la condición femenina (Ponce \& La Rosa, 1995), encuentran su máxima expresión en la madre.

En un trabajo reciente Fernández (1998) encontró que, si bien conversar con la madre no es la variable más importante para predecir las relaciones sexuales en universitarios, sigue teniendo una influencia significativa en la decisión de tenerlas o no, sobre todo entre las mujeres. Podemos, por ello, afirmar que una buena relación con los padres, especialmente con la madre, y la aceptación de valores tradicionales, ayudan a retrasar el inicio de las relaciones sexuales.

Esto es comprensible, pues para muchos adolescentes la madre es el princi- 
pal referente afectivo. De acuerdo con La Rosa (1997), en un estudio con adolescentes de colegios estatales, para el $41 \%$ la principal figura en el plano emocional es la madre, acudiendo a ella en caso de problemas (34,5\%), más que al amigo (25\%) y al padre $(6 \%)$.

\section{La figura paterna}

Mientras que la figura materna siempre ha sido muy valorada como modelo y ejemplo a seguir, y como crucial en la vida futura de los hijos, la revalorización de la figura del padre ocurrió sólo hace poco (Munder Ross, 1979). Personaje distante, alejado, poco afectuoso, el rol del padre en el pasado fue el de proveedor del sustento del hogar y el de jefe de familia (Textor, 1990).

Mucho de esto se conserva aún en nuestros días. Silvestre et al. (1996) anotan que "la madre continúa siendo en la adolescencia de sus hijos e hijas la que se comunica con mayor frecuencia y eficacia con ellos y ellas" y observan que "en cuanto a la relación con el padre se señala que se vive más autoritariamente y que aporta elementos respecto al mundo general (política, cultura...)" (p. 34).

Sin embargo, se han producido cambios evidentes. Textor observa que "el esposo y padre no posee más la autoridad de antes, no representa más de modo único a la familia y determina menos la conducta de los miembros de ésta" (1990, p. 46), pero al mismo tiem- po se ha elevado su responsabilidad en la educación de los hijos.

Ahora bien, no sólo la importancia del padre parece haber disminuido. Podríamos decir que dicha disminución afecta a la familia en general. Fernández (1998) encontró que los porcentajes de sujetos que señalan que la familia es la principal fuente de información sexual son semejantes a los que señalan a los amigos, revistas y medios de comunicación. Dentro de la familia, la madre aparece como la interlocutora preferida para tratar temas sexuales y en toda suerte de problemas en general.

Esto, que por cierto no sólo ocurre en el Perú, se debe en parte al hecho de que la educación sexual que se otorga en el hogar no es lo suficientemente articulada (Masters et al., 1996), por lo cual los adolescentes recurren a otras fuentes de información (como las señaladas en el párrafo anterior).

\section{La religión}

La religión es vista como una poderosa fuerza reguladora del comportamiento sexual. El cristianismo, la religión más difundida en Occidente, ha intervenido de modo decisivo en temas como el control de la natalidad, el amor libre, la masturbación, la homosexualidad, etc.

Es plenamente justificada, por ello, la afirmación de Mindreau \& Morales (1996), en el sentido de que "hablar de religión y sexualidad suponen necesariamente referirse a un tipo de relación 
unidireccional en la que la primera es factor históricamente influyente en la segunda" (p. 209). En efecto: Giddens (1998) escribe que "la confesión católica (...) fue siempre un medio de regular la vida sexual de los creyentes" (p. 29).

\section{El temor al qué dirán}

El temor al qué dirán es reconocido como una fuerza de gran poder inhibitorio en la vida social en el Perú, en la que es frecuente una gran preocupación con respecto a la opinión negativa de los demás con respecto a uno (GlassCoffin, 1988).

El tema no ha sido abordado con la intensidad que su significado merece. Por ello sólo tenemos información tangencial: así, por ejemplo, en un trabajo previo llevado a cabo por uno de nosotros, se encontró que los encuestados creían que en el Perú la gente es muy "rajona" (León \& Moscoso, 1991).

¿De qué raja la gente en el Perú? No se tiene una información sistemática sobre el particular, en parte por lo singular y lo privado del tema (Ben-Ze'ev, 1994). Pero una conclusión basada en las impresiones acumuladas en la vida cotidiana permite afirmar que los temas sexuales ocupan un lugar de gran importancia.

Obviamente, el temor al qué dirán está vinculado con el miedo al escándalo (Fine \& Rosnow, 1978), o sea aquella situación social en la cual nuestra imagen y nuestro buen nombre son puestos en entredicho ante los demás por algu- na acción o rasgo negativo de nosotros que es severa y públicamente desaprobado por la sociedad (Bergmann, 1993).

La mujer en la sociedad peruana parece más propensa a dejarse influir por el temor al qué dirán. Son numerosas las situaciones en las cuales ella debe tener muy en cuenta la opinión de los demás. Su conducta en su relación con las personas del sexo opuesto, la preservación de la virginidad hasta el matrimonio, la regulación del comportamiento de modo tal que ella no sea vista como una "mujer fácil", son sólo algunas de esas situaciones.

\section{El impulso sexual}

El impulso sexual es la expresión subjetiva de la fuerza del deseo sexual. Giraldo Neyra (1989) lo define como "el deseo de descarga y de tensión y creación de la misma, por medio de actos o fenómenos que de modo directo o indirecto incluyen los órganos sexuales y sus reacciones biológicas" (p. 12). Se trata del componente más biológico de la sexualidad. El impulso sexual varía en la misma persona por épocas (McCary \& McCary, 1990) y está condicionado por numerosas circunstancias: así, un estado de buena salud tiende a facilitar el deseo y placer sexuales (Baldwin \& Baldwin, 1994). Entre los elementos no biológicos están la ansiedad, la inseguridad, los estados de ánimo (Masters et al., 1996). 
El impulso sexual es experimentado de modo diferente por uno y otro sexo. La Rosa (1997) lo describe:

Para el varón el impulso sexual encuentra una expresión relativamente precisa y explícita en órganos externos que son para él fuentes conocidas y familiares de placer. El varón por lo menos conoce la naturaleza y la ubicación de sus impulsos en una forma precisa y explícita que, biológicamente, no es accesible a la mujer. En la mujer, los órganos sexuales primarios son internos y están ocultos, por lo que el despertar de la sexualidad asume formas más difusas y ambiguas -sensibilidad cutánea, lubricación vaginal y excitación difusa de la región pélvica (p. 89).

El estereotipo de una sexualidad masculina irrefrenable, descontrolada, tiene vigencia entre personas de uno y otro sexo de diversas edades y condiciones socioeconómicas, lo cual justifica para los varones de todos los estratos la infidelidad a su pareja (Yon Leau, 1996).

\section{La educación sexual}

La educación sexual es la información sistemática que se transmite en el colegio acerca de la sexualidad humana en el marco de los programas educativos que promueve el Estado. Sus objetivos son desmitificar la sexualidad, informar acerca de los mecanismos y el sentido de ella, prevenir enfermedades venéreas, y favorecer el desarrollo de una sexualidad sana. Su efectividad suele ser vista como elevada: se ha demostrado que hay correlación entre la educación sexual y los niveles bajos de culpa sexual, y en la reducción de la frecuencia de las enfermedades venéreas (McCary \& McCary, 1990).

Giraldo Neyra (1989) señala que la educación sexual se compone de tres aspectos: las actitudes, las vivencias y la información. En el dominio de las vivencias, la educación sexual persigue vincular la sexualidad con sentimientos de afecto (el amor) hacia otra persona, y al mismo tiempo, desarrollar una clara conciencia del significado de la sexualidad en la personalidad de cada cual. En lo actitudinal, la educación sexual busca desarrollar el sentido de responsabilidad frente a las relaciones sexuales enfatizando el control y la canalización del impulso sexual. Por último, en lo que atañe a la información, se trata de ofrecer conocimientos claros y fundamentados de la sexualidad, los órganos y relaciones sexuales y los métodos de control de la natalidad.

La valoración actual de la educación sexual se caracteriza por el reconocimiento de que algunos aspectos de ella no funcionan adecuadamente. Masters et al., (1996) emiten la siguiente opinión al respecto:

Existen pocas indicaciones de que transmitir información sea, por sí solo, algo que cambie el comportamiento sexual de los adolescentes de una forma significativa, que es sin duda el motivo por el que la mayoría de los programas de educación sexual impartidos en los colegios no han demostrado ser eficaces para reducir el índice de la actividad se- 
xual o los embarazos no deseados entre los adolescentes. Además, muchos programas de educación sexual cargan tanto las tintas sobre la noción de abstinencia por parte de los adolescentes, que los estudiantes de bachillerato superior tienden a hacer caso omiso de estas recomendaciones (pp. 494-495).

\section{Las amistades}

Las amistades poseen gran significado en la vida de las personas. Buena parte de la información que manejan los adolescentes proviene de su grupo de amigos y de los medios masivos de comunicación (Atkin, 1991; La Rosa, 1997).

Los grupos de pares ("colleras", "manchas o pandillas") son, como lo señala La Rosa, "núcleos centrales en la vida de los adolescentes y les permiten desarrollar su identidad mediante la experimentación de situaciones nuevas" (p. 41).

Estudios previos demuestran que los amigos son fuente de información sobre la sexualidad. León y Cossío de Preciado (1993) encontraron en adolescentes limeños que el $51,2 \%$ de varones señalaba a los amigos como fuente de los primeros conocimientos sexuales, lo mismo que el $30,9 \%$ de mujeres. Estas frecuencias elevadas se explican cuando se considera que, como lo anotan Silvestre et al. (1996), la amistad en la adolescencia es la primera oportunidad para compartir recíprocamente la propia intimidad.

Asimismo, Fernández (1998) reporta que la principal fuente de información, señalada por universitarios de Lima, es la familia $(55,5 \%)$, seguida por los amigos $(53,7 \%)$ y por la literatura especializada $(50,7 \%)$. De igual manera, Sears (1984) afirma que el desarrollo sexual ocurre aislado de la influencia de los adultos y, más bien, directamente vinculado a los grupos de compañeros, en lo que puede entenderse como una "cultura de pares".

\section{La curiosidad sexual}

La curiosidad sexual es una forma de conducta exploratoria vinculada al despertar de la sexualidad, algo que ocurre en la etapa puberal. Se puede, por supuesto, reconocer la curiosidad por el sexo ya en la infancia (como cuando por ejemplo los niños juegan al papá y a la mamá, o al doctor, inspeccionando los órganos genitales de los otros niños), que es estimulada por la marcada tendencia en la cultura occidental a cubrir las zonas genitales (Giraldo Neyra, 1989).

\section{El peligro del sida}

El sida es una sombría realidad nueva identificada de modo concluyente en 1981, y que se ha constituido en una causa de invalidez y muerte cada vez mayor, con inconmensurables costos económicos, sociales y emocionales para los infectados así como para sus amigos y familiares. En 1994 Wilbur señalaba que en los diez años siguientes una de cada diez personas en Estados Unidos contraerían el sida (Wilbur, 
1994). En un artículo reciente se estima que a fines de 1998 más de 33 millones de personas estaban infectadas y que 14 millones habían fallecido (Chakraborty \& Rowland-Jones, 1999).

Richardson (1990) observa que el sida reúne aspectos que la sociedad trata de evitar, tales como la homosexualidad, las enfermedades sexuales, el uso de drogas y la muerte, e implica, además, comentar actividades que para muchos son innombrables.

El sida ha dado nuevo ímpetu a los programas de educación sexual, una de cuyas metas más importantes antes de su aparición era el control de natalidad, y ha originado una revisión de las conductas y actitudes sexuales de los individuos, así como cambios en las políticas públicas. Así, en 1991 la Comisión Nacional sobre el Sida en Estados Unidos recomendó la abolición de barreras legales para la compra de jeringas descartables por parte de drogadictos, con la finalidad de prevenir el contagio entre ellos (Wilbur, 1994).

En la actualidad, la infección del VIH y el Sida se encuentran entre las tres principales causas de muerte de los hombres de edades comprendidas entre los quince y los cuarenticuatro años en Estados Unidos, y son una de las principales causas de años de pérdida potencial de vida tanto para hombres como para mujeres, entre las personas de veinte a treintinueve años. (Masters et al., 1996).

El sida se ha convertido, por último, en la fuerza de mayor significado en contra de relaciones sexuales con per- sonas por las cuales no se siente afecto. Walsh (1991) informa que en un estudio de 12 mil varones y mujeres solteros entre 1966 y 1986, se encontró que en $196672,6 \%$ de varones y $43,3 \%$ de mujeres habían tenido relaciones sexuales con alguien a quien no querían, mientras que 20 años más tarde los porcentajes eran $48,8 \%$ y $17,9 \%$, respectivamente.

\section{El autocontrol sexual}

El autocontrol es la capacidad voluntaria y consciente del individuo para regular su vida sexual. Es estimulado tanto en la educación se-xual en los colegios como en la formación que se da en el hogar, en el cual se insiste mucho en la necesidad de la virginidad en las mujeres solteras.

El supuesto fundamental es que la sexualidad es una verdadera bomba de tiempo. Por lo mismo, es necesario normarla, ordenarla y reprimirla.

El autocontrol fue en el pasado el factor de mayor significación social para regular la sexualidad. Thomas Nipperdey describe la atmósfera en torno al sexo en la Alemania de comienzos de siglo, que fue también la que caracterizó al mundo occidental:

Autocontrol, reflexión y moderación, decencia, sobriedad, laboriosidad, orden y normalidad, éstas fueron las virtudes burguesas, pero vinculadas de modo indisoluble a ellas estaba el control de la vida y el dominio de la sexualidad, y esto significaba en el contexto social un comportamiento sexual ajustado a las 
normas: control, normalidad y respetabilidad burguesa... (1993, pp. 95-96).

Pero no sólo a través de la educación sino también por medio de la superstición se buscó desarrollar el autocontrol en el terreno sexual: entre los siglos XVI y XVIII era frecuente la creencia de que con cada acto sexual la vida del varón se reducía en un día (Crawford, 1994).

En nuestro medio, Fernández (1998) reporta que, con respecto al control interno afectivo, los estudiantes de la universidad privada evidencian un mejor control que los de la universidad estatal, en tanto que los que no tienen relaciones sexuales muestran también un mejor control que los que sí la tienen. Finalmente, los que no tienen relaciones sexuales revelan un mayor apego a la obediencia que los que sí la tienen.

\section{La ocasión}

La ocasión designa la posibilidad de tener experiencias sexuales por razones circunstanciales. Esto último ocurre con una frecuencia alta, en especial entre los varones. Y ocurre, además, sin que se tomen medidas de protección, inclusive entre quienes han recibido educación sexual, pues, como lo señalan Fernández-Ríos et al. (1997, p. 71),

en líneas generales, ni las tasas de actividad sexual ni la eficacia de los procedimientos anticonceptivos, ni los embarazos han sido prevenidos como un resultado de los programas preventivos de educación sexual.
La aparente mayor proclividad de los varones a tener relaciones sexuales provocadas por la ocasión está así mismo influida por la presión social para que ellos ganen experiencia en el terreno de la sexualidad antes del matrimonio (La Rosa, 1997).

\section{La sexualidad en las diferentes regiones}

El Perú es un país escindido. La accidentada geografía, los precarios sistemas de comunicación y la variedad de culturas que conviven dentro de las fronteras del país, contribuyen a esa escisión y al desconocimiento recíproco. Desconfianzas, recelos, temores y prejuicios reemplazan el conocimiento objetivo. Estereotipos y generalizaciones desmesuradas menudean entre nosotros: el costeño (quien vive a nivel del mar) es vivaz y hospitalario; el andino (quien habita en las zonas altas de nuestro país), frío e introvertido; y el selvático alegre y despreocupado.

Se trata obviamente de estereotipos, uno de los temas a los que la psicología social presta más atención. Un reciente texto de psicología social los entiende como "imágenes mentales simplificadas de cómo son vistos los grupos y qué hacen" (Smith \& Mackie, 1997; p. 177), agregando que:

los estereotipos hacen formulaciones de cómo son los grupos: los rasgos de personalidad que se cree comparten sus miembros y las emociones y sentimientos que los miembros del grupo despiertan en los demás. 
Un dominio de la existencia humana de tanto significado como es el de la sexualidad, no podía escapar a los estereotipos. El macho latino, el eslavo y el italiano apasionados, son sólo expresiones de esa tendencia de los seres humanos a establecer denominadores comunes que ordenen y den sentido al complejo mundo de las relaciones sociales. Lo mismo sucede en la sexualidad del peruano.

\section{Material y método}

Se diseñó un reactivo con 42 ítems que evaluaban la importancia que se concede a un conjunto de fuerzas biológicas, personas e instituciones en la sexualidad de varones y mujeres. La importancia de la madre, del padre, de la religión, del temor al qué dirán, del impulso sexual, de la educación sexual en el colegio, de las amistades, de la curiosidad sexual, del peligro del sida, del autocontrol y de la ocasión, fueron evaluados para las actitudes y conductas sexuales de hombres y mujeres a través de una escala tipo Likert.

Los ítems fueron sometidos a análisis factorial usando el método de matriz de covarianzas. Surgieron seis factores, que explicaron el $37,1 \%$ de la varianza. El factor 1, Intercambio de información en materia de sexualidad, con cinco ítems (alpha: .6877); el factor 2, Contexto social de sexualidad, con nueve ítems (alpha: .6162); el factor 3, Estereotipos acerca de la fuerza del impulso sexual, con seis ítems (alpha:
.7116); el factor 4, Control moral de la sexualidad, con seis ítems (alpha: .6518): el factor 5, Autocontrol y temores en sexualidad, con seis ítems (alpha: .6106); y el factor 6, Importancia de la sexualidad, con tres ítems (alpha: .6201).

Se evaluó asimismo la importancia que cada persona asignaba al sexo para los seres humanos en general, para ella misma, para una persona de sexo masculino y para una de sexo femenino. Se indagó también acerca de la frecuencia con la que pensaban en el sexo, con la cual creían que hombres y mujeres pensaban en el sexo; y la frecuencia con la cual creían que los hombres y las mujeres de su edad hablaban de sexo con sus amistades.

Además, se estudiaron dos áreas: Una, la percepción que se considera que tiene la sociedad peruana de un hombre que ha tenido relaciones sexuales antes del matrimonio, así como de una mujer que ha hecho lo mismo; la otra, la atribución de fuerza del impulso sexual al hombre y a la mujer de la sierra, al hombre y a la mujer de la costa, y al hombre y a la mujer de la selva.

Se seleccionó intencionalmente a 1.295 personas, cuyas edades eran entre los 16 y 29 años; 601 fueron varones y 694 mujeres. Todos ellos cursaban estudios en universidades privadas y estatales en Lima. 


\section{Resultados}

\section{Importancia asignada al sexo}

Veamos en primer lugar qué importancia conceden los encuestados al sexo en la especie humana. El gráfico $\mathrm{N}^{\circ}$ 1 presenta los resultados.

\section{Gráfico № 1}

Valoración de la importancia del sexo para el ser humano en general

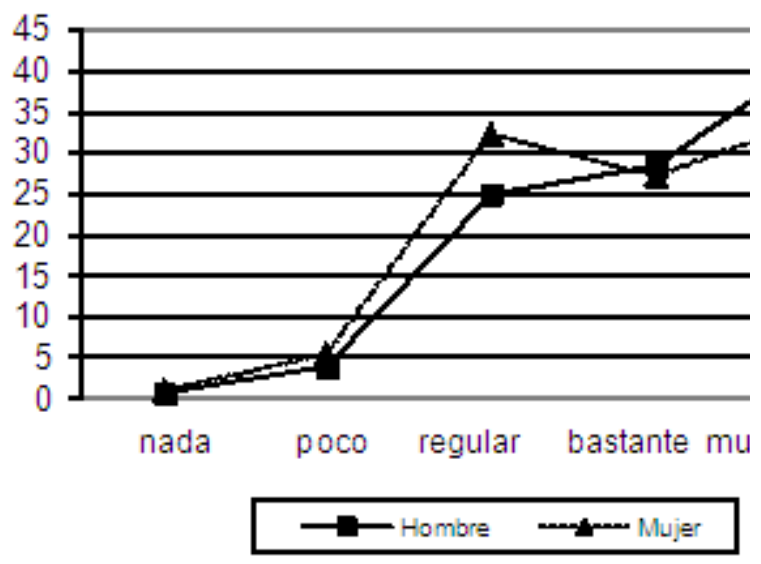

Encontramos que ambos sexos coinciden en reconocer la importancia de la sexualidad. Este reconocimiento es, sin embargo, más pronunciado en los varones, entre los cuales el 70,3\% lo considera como bastante y muy importante vs. el $61,3 \%$ de $(\mathrm{p}<0.01448)$.

\section{Gráfico $\mathbf{N}^{\circ} 2$}

Valoración de la importancia que las personas conceden al sexo para sí mismas

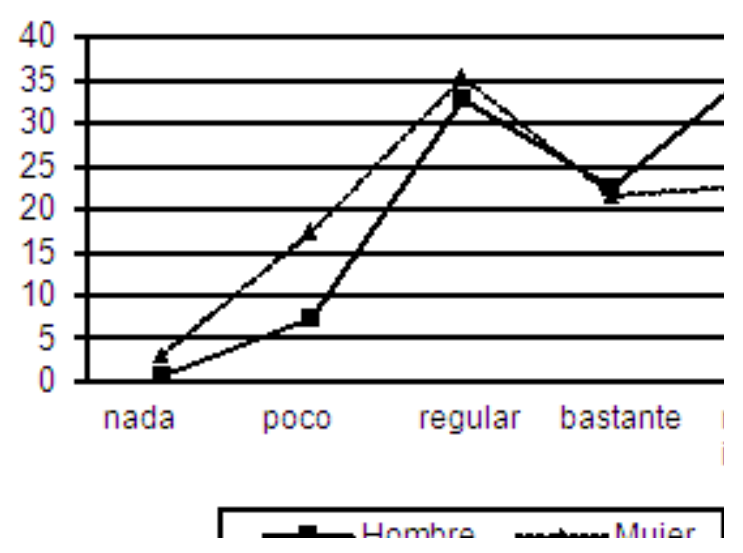

Una vez más, los varones son los que atribuyen mayor importancia al sexo en sus vidas (si bien entre ellos se puede observar porcentajes relativamente parecidos que lo consideran regular $-33,8 \%$ - у muy importante $-36,9 \%$ ), mientras que las mujeres, en mayor porcentaje, lo consideran regular $(35,3 \%$, $\mathrm{p}<0.00000$ ).

Sólo $22,9 \%$ de ellas opta por la alternativa muy importante.

Nadie duda, en efecto, de la importancia de la sexualidad en la vida de los seres humanos, y tampoco acerca del significado de ella en la propia existencia. Pero es claro, también, que esa importancia suele ser considerada como diferente para los hombres y para las mujeres. 
Gráfico N ${ }^{\circ} 3$

Importancia concedida por hombres y mujeres al sexo en las personas de sexo masculino

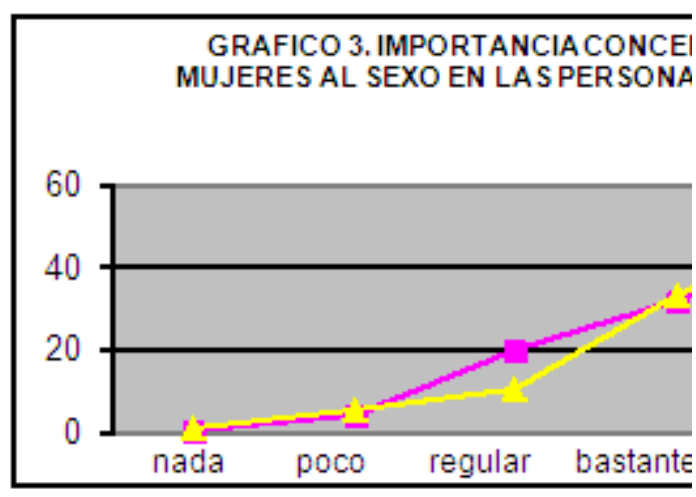

En el gráfico $\mathrm{N}^{\circ} 3$ se muestra que hombres y mujeres coinciden en atribuir gran importancia al sexo para las personas del sexo masculino, pero son las mujeres las que creen más que los propios varones, que el sexo tiene más importancia para ellos: $83,3 \%$ de las personas del sexo femenino lo considera bastante y muy importante para los hombres vs. $75,5 \%$ de los varones $(\mathrm{p}<0.00003)$.

En el gráfico $\mathrm{N}^{\circ} 4$ se observa que, a diferencia de lo ocurrido con la sexualidad masculina, considerada como muy importante, en el caso de la femenina ésta es vista por hombres y por mujeres como de regular importancia (41,6\% y $42,1 \%$, respectivamente).
Gráfico $N^{\circ} 4$

Importancia concedida por hombres y

mujeres al sexo en las personas del sexo femenino

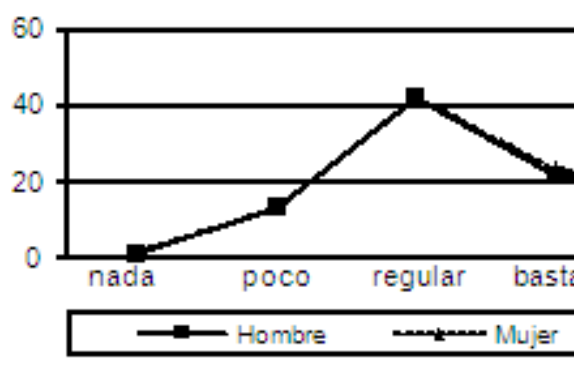

Resumiendo la información contenida en los gráficos 3 y 4 puede concluirse que la muestra mayoritariamente es del parecer que la dimensión sexual es de mucha mayor importancia para los hombres que para las mujeres.

Los temas importantes en la vida de las personas concitan su atención, sus ideas, y las llevan a tratarlos con los demás. Nos interesó explorar la frecuencia con la cual los sujetos afirman pensar en el sexo, y con la que creen que hombres y mujeres piensan en el sexo, respectivamente.

\section{Gráfico $\mathrm{N}^{\circ} 5$}

Frecuencia con la cual las personas afirman pensar en el sexo

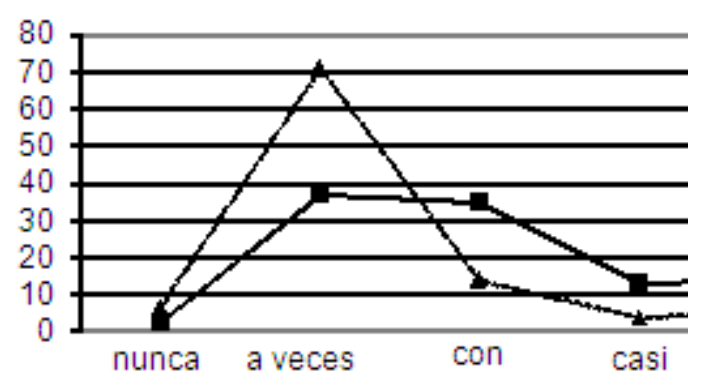


Sólo porcentajes muy bajos afirman no pensar en el sexo nunca ( $2 \%$ entre los varones y $6,8 \%$ entre las mujeres). Destaca, en particular, que la mayoría de mujeres dice que piensan en él sólo a veces $(70,7 \%$ vs. $36,9 \%$ de varones). La opción con frecuencia es elegida por $34,4 \%$ de varones, pero sólo por $13,3 \%$ de mujeres. Por otro lado, el $14 \%$ de varones refieren que piensan siempre, vs. 5,6\% de mujeres que afirma lo mismo $(\mathrm{p}<0.00000)$.

\section{Gráfico $\mathbf{N}^{\circ} 6$}

Frecuencia con la cual las personas afirman conversar acerca del sexo con sus amistades

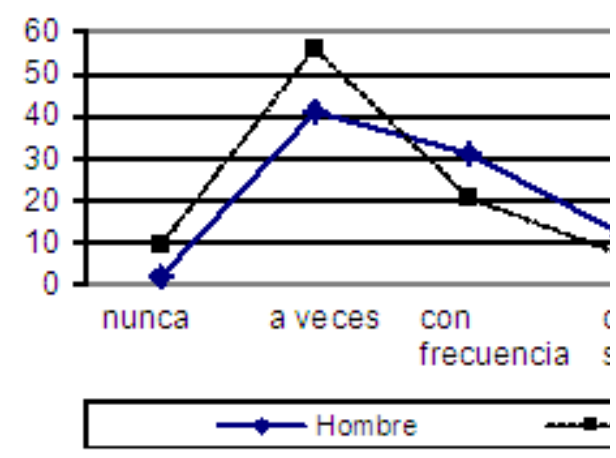

Tanto hombres como mujeres optan en su mayoría por la alternativa a veces $(41,1 \%$ de varones y $59,9 \%$ de mujeres), pero mientras que el $25,9 \%$ de varones señala que casi siempre o siempre habla de sexo con sus amigos, sólo $12 \%$ de mujeres afirma lo mismo $(\mathrm{p}<0.00000)$.

Ya hemos observado que los encuestados atribuyen mayor peso al sexo para las personas del sexo masculino que para el femenino, pero ¿cómo valoran ellos la frecuencia de pensamientos sexuales en cada uno de los sexos?

\section{Gráfico $\mathrm{N}^{\circ} 7$}

Frecuencia con la cual hombres y mujeres creen que las personas del sexo masculino piensan en el sexo
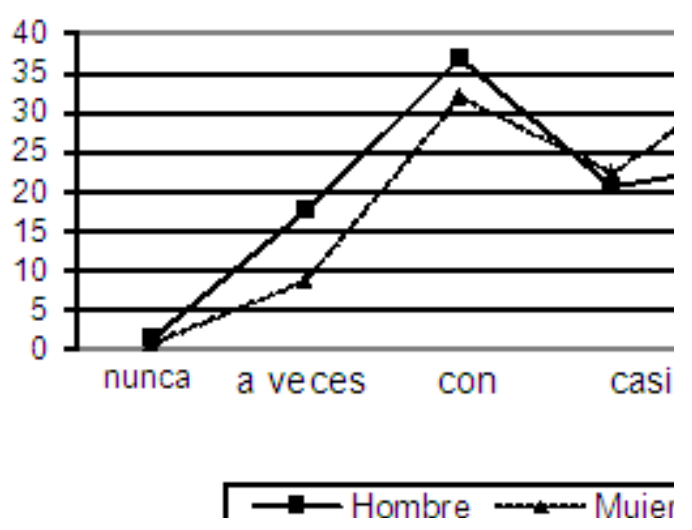

El gráfico $\mathrm{N}^{\circ} 7$ muestra que las mujeres son del parecer que los hombres piensan frecuentemente en el sexo, en un porcentaje mayor que los propios varones: $58,8 \%$ opta por casi siempre o siempre, vs. $43,8 \%$ de varones $(\mathrm{p}<0.00000)$.

\section{Gráfico $\mathrm{N}^{\circ} 8$}

Frecuencia con la cual hombres y mujeres creen que las personas del sexo femenino piensan en el sexo

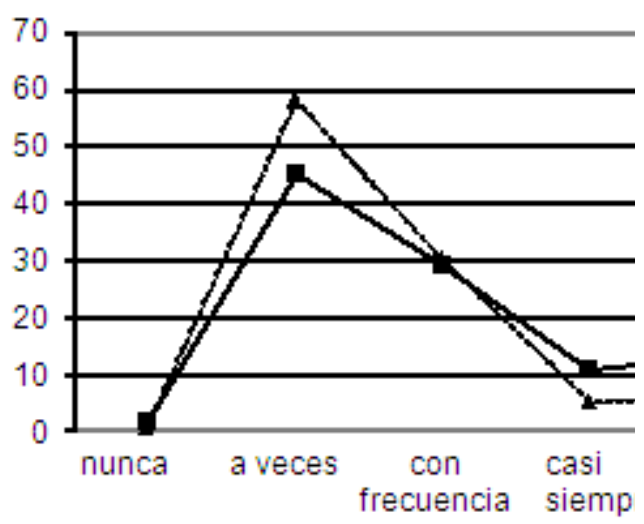


En el gráfico $\mathrm{N}^{\circ} 8$, a diferencia del anterior, en el cual hombres y mujeres atribuyen alta frecuencia de pensamientos sexuales a los varones se observa exactamente lo opuesto: $45,3 \%$ de los hombres y 58,2\% de las mujeres son del parecer que las mujeres sólo a veces piensan en el sexo. Llama la atención, inclusive, que son más los hombres $(23,9 \%)$ que las mujeres $(11 \%)$ los que son del parecer que las personas del sexo femenino piensan en el sexo casi siempre o siempre $(p<0.00000)$.

\section{Gráfico $\mathbf{N}^{\circ} 9$}

Frecuencia con la cual hombres y mujeres creen que los hombres de su edad hablan del sexo con sus amigos
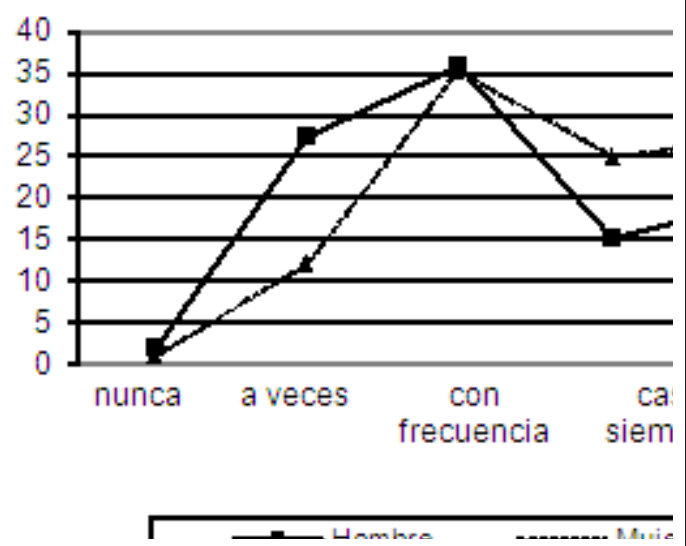

En el gráfico $\mathrm{N}^{\circ} 9$ encontramos que si bien hombres y mujeres en porcentajes similares $(35 \%)$ concuerdan en que los hombres hablan del sexo con sus amigos con frecuencia, las mujeres son del parecer que los temas sexuales son tratados por los varones con los amigos casi siempre o siempre (52\%, vs. $24,9 \%$ de varones; $\mathrm{p}<0.00000)$.
Gráfico No 10

Frecuencia con la cual hombres y mujeres creen que las mujeres de su edad hablan del sexo con sus amigas

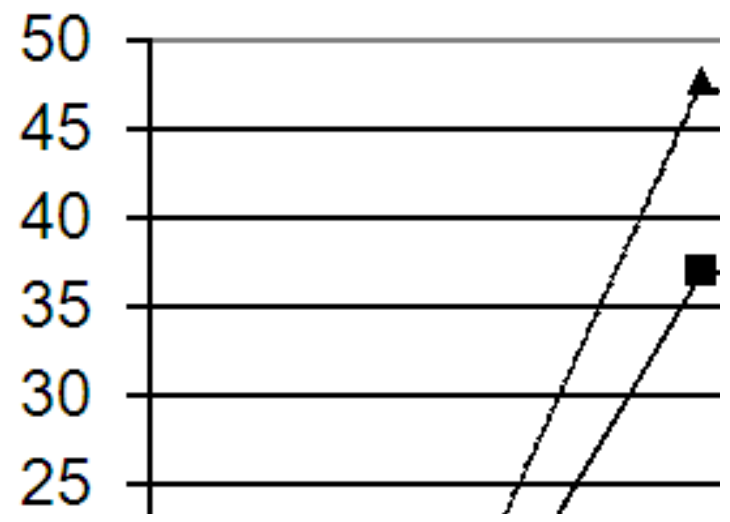

En el gráfico $\mathrm{N}^{\circ} 10$ se observa que las mujeres son vistas como más reservadas en materia de sexualidad, tanto por parte de los varones como por las mujeres mismas: sólo $24,4 \%$ de ellos y $16,7 \%$ de ellas creen que hablan siempre o casi siempre de sexo $(\mathrm{p}<0.00039)$.

\section{VARIABLES EN LAS ACTITUDES Y \\ CONDUCTAS SEXUALES}

¿Cuán importantes son -según la muestra- las diferentes variables consideradas en esta investigación como determinantes de la conducta sexual? La tabla 1 presenta las respuestas a esta pregunta.

La atribución por el grupo total de la importancia de diversas variables en las actitudes y las conductas sexuales es diferente, según se trate de la sexualidad de los varones o de la sexualidad de las mujeres. 
En la sexualidad masculina la curiosidad y el impulso sexuales (este último, una variable de corte biológico) se encuentran en primer lugar, seguidos de las amistades y del riesgo de contraer sida. En las mujeres el peligro de contraer sida es el que ocupa el primer lugar, seguido por la influencia de la madre, por el autocontrol y por el temor al qué dirán.

Obsérvese que mientras que el impulso sexual es considerado entre los más poderosos determinantes de la sexualidad del varón, su importancia es vista como mucho menor en la mujer, lo cual expresa una vez más la difundida idea de que la sexualidad del varón es mucho más intensa.

Llama la atención, de otro lado, la escasa influencia que el grupo en general concede a la educación sexual en el colegio cuando se trata de la sexualidad masculina, mientras que en el caso de las mujeres la importancia que le es atribuida es algo mayor.

Asimismo, destaca el mínimo valor que se concede a la religión como fuerza reguladora de la sexualidad de varones y mujeres.

Desagreguemos ahora esta tabla en dos, tomando en consideración lo que los hombres y las mujeres de la muestra piensan acerca de la importancia de las diferentes variables en la sexualidad masculina, y después, lo que piensan sobre dichos factores en referencia a la sexualidad de la mujer.

Es interesante observar la diferente valoración de la influencia de los factores considerados por parte de hombres y mujeres en lo que atañe a la sexualidad masculina.

Los hombres consideran que la posibilidad de contraer el sida es la mayor

Tabla $N^{\circ} 1$

Adjudicación de importancia de variables culturales y biológicas en la conducta y actitudes sexuales por parte de todo el grupo

\begin{tabular}{lcll}
\hline Influencia en los varones de: & $\bar{X}$ & Influencia en las mujeres de: & $\bar{X}$ \\
\hline Curiosidad sexual & & & \\
Impulso sexual & 4.05 & Peligro del sida & 4.31 \\
Amistades & 4.02 & Madre & 4.15 \\
Peligro del sida & 3.95 & Autocontrol & 3.97 \\
Padre & 3.86 & Temor al qué dirán & 3.83 \\
Ocasión & 3.80 & Amistades & 3.64 \\
Autocontrol & 3.76 & Educación sexual & 3.57 \\
Madre & 3.37 & Curiosidad sexual & 3.50 \\
Educación sexual & 3.33 & Ocasión & 3.44 \\
Temor al qué dirán & 3.24 & Impulso sexual & 3.41 \\
Religión & 2.62 & Padre & 3.31 \\
& 2.59 & Religión & 3.24
\end{tabular}


Tabla $\mathbf{N}^{\circ} 2$

Adjudicación de importancia de variables culturales y biológicas en la conducta y las actitudes sexuales de los varones atribuida por hombres y mujeres a los diferentes factores en las actitudes y conductas sexuales en los varones

\begin{tabular}{llll}
\hline Hombres & $\overline{\mathrm{X}}$ & Mujeres & $\overline{\mathrm{X}}$ \\
\hline & & & \\
Peligro de sida & 4.22 & Curiosidad sexual & 4.15 \\
Curiosidad sexual & 3.95 & Impulso sexual & 4.13 \\
Impulso sexual & 3.90 & Padre & 4.07 \\
Padre & 3.82 & Amistades & 3.96 \\
Ocasión & 3.76 & Ocasión & 3.77 \\
Autocontrol & 3.69 & Peligro de sida & 3.56 \\
Amistades & 3.60 & Madre & 3.46 \\
Educ. sexual en el colegio & 3.32 & Educ. sexual en el colegio & 3.17 \\
Madre & 3.18 & Autocontrol & 3.09 \\
Religión & 2.70 & Temor al qué dirán & 2.57 \\
Temor al que dirán & 2.67 & Religión & 2.49 \\
\hline
\end{tabular}

influencia, seguida por la curiosidad y el impulso sexuales. La figura paterna es considerada la cuarta en importancia. Llama la atención, de otro lado, el escaso significado que los hombres conceden a la educación sexual recibida en el colegio como fuerza orientadora de la sexualidad masculina. Todavía mucho menor es, como puede verse, la que le conceden a la religión.

Las mujeres tienen una percepción parcialmente diferente. Como los varones, conceden valor relativo a la educación sexual en la sexualidad masculina, pero a diferencia de ellos colocan a la curiosidad y al impulso sexual como los condicionamientos más importantes. Después de ellos, el padre es la fuerza de mayor peso. Entre tanto, el peligro del sida es visto como una influencia de significado medio.
Finalmente, como en el caso de los hombres, también las mujeres dan mínimo significado al temor, al qué dirán y a la religión.

Veamos ahora qué sucede en materia de las variables que influyen en la sexualidad femenina.

A diferencia de lo ocurrido en el caso de los varones, los encuestados tanto hombres como mujeres muestran unanimidad en considerar el peligro del sida como la fuerza reguladora de mayor potencia, seguida por la figura materna, el autocontrol y el qué dirán.

Una vez más la educación sexual es vista como una variable de poder más bien relativo (ocupa el sétimo lugar en los hombres y el quinto en las mujeres). Asimismo, también en el caso de la sexualidad femenina la religión es vista como de mínimo peso. 
Tabla $\mathbf{N}^{\circ} 3$

Importancia atribuida por hombres y mujeres a los diferentes condicionamientos en las actitudes y conducta sexuales de las mujeres

\begin{tabular}{llll}
\hline Hombres & $\overline{\mathrm{X}}$ & Mujeres & $\overline{\mathrm{X}}$ \\
\hline Peligro del sida & & & \\
Madre & 4.25 & Peligro del sida & 4.36 \\
Autocontrol & 4.12 & Madre & 4.17 \\
Temor al qué dirán & 3.93 & Autocontrol & 4.01 \\
Amistades & 3.78 & Temor al qué dirán & 3.88 \\
Curiosidad sexual & 3.67 & Educ. sexual en el colegio & 3.62 \\
Educ. sexual en el colegio & 3.63 & Amistades & 3.61 \\
Impulso sexual & 3.51 & Ocasión & 3.42 \\
Ocasión & 3.46 & Padre & 3.39 \\
Padre & 3.46 & Curiosidad sexual & 3.38 \\
Religión & 3.21 & Impulso sexual & 3.27 \\
\hline
\end{tabular}

Pero el hallazgo más importante se observa en lo que se refiere al impulso y la curiosidad sexuales, que en el caso de la sexualidad femenina son vistas como fuerzas de no mucho significado.

Los promedios constituyen como se sabe una medida general, que no puede reflejar los detalles de la distribución de los puntajes que les han dado origen.

La tabla 4 agrupa los porcentajes obtenidos para cada uno de los factores en calidad de influencia de la conducta sexual de los varones y las mujeres.

Puede verse en el caso de la madre, que las mujeres le atribuyen en mayor proporción que los varones influencia en la conducta y actitudes sexuales masculinas $(48,4 \%$, frente a $38,6 \%$ de los hombres, selecciona las alternativas bastante y muy importante; $\mathrm{p}<0.00022$ ). No sucede lo mismo cuando se evalúa su influencia en las mujeres, pues sobre el particular hay semejanza de porcentajes $(75 \%$ de varones y $77,9 \%$ de mujeres creen que la madre influye bastante o muy importante). Esto es, la influencia de la figura materna es vista de modo diferenciado: más bien relativa en los varones pero elevada para las mujeres.

En lo que concierne al padre, las mujeres son del parecer que él influye mucho en el varón $(74,4 \%$ optan por atribuirle bastante y muy importante influencia, mientras que el porcentaje de varones que hace lo mismo es de $61,6 \% ; \mathrm{p}<0.00001)$. Nuevamente, hay alguna semejanza de porcentajes de mujeres $(45,4 \%)$ y varones $(38,4 \%)$ en la atribución de la influencia del padre en la conducta y actitudes sexuales de la mujer. 
Tabla $\mathbf{N}^{\circ} 4$

Porcentajes de la atribución de influencia en la conducta y actitudes sexuales en varón y mujer para cada una de las variables exploradas

\begin{tabular}{|c|c|c|c|c|c|c|c|c|c|c|c|c|c|}
\hline \multirow{4}{*}{$\begin{array}{l}\text { Influencia de } \\
\text { La madre }\end{array}$} & & \multicolumn{2}{|c|}{$\mathrm{Nada}$} & \multicolumn{2}{|c|}{ Poco } & \multicolumn{2}{|c|}{ Regular } & \multicolumn{2}{|c|}{ Bastante } & \multicolumn{2}{|c|}{ Miluy } & \multirow{3}{*}{$\begin{array}{c}V \\
0.12974\end{array}$} & \multirow{3}{*}{$\begin{array}{c}\text { NS } \\
0,00022\end{array}$} \\
\hline & & $\mathrm{H}$ & $M$ & $\mathrm{H}$ & $M$ & $\mathrm{H}$ & $M$ & $\mathrm{H}$ & $M$ & $\mathrm{H}$ & $M$ & & \\
\hline & Varón & 7.3 & 3.3 & 25.0 & 232 & 29.1 & 25.1 & 18.6 & 20.2 & 200 & 28.2 & & \\
\hline & Mujer & 1.0 & 1.6 & 6.5 & 6.2 & 17.5 & 143 & 28.6 & 29.1 & 45.4 & 48.8 & 0.05133 & 0.49128 \\
\hline \multirow{3}{*}{ El padre } & Varón & 2.2 & 2.6 & 12.3 & 8.4 & 24.0 & 14.7 & 24.5 & 27.7 & 370 & 46.6 & 0.14706 & 0.00001 \\
\hline & Mujer & 5.0 & 4.3 & 28.8 & 229 & 27.8 & 27.4 & 16.6 & 19.9 & 218 & 25.5 & 0.08041 & 0.07880 \\
\hline & Varón & 16.6 & 180 & 32.9 & 415 & 27.1 & 23.6 & 10.3 & 6.5 & 130 & 10.5 & 0.11043 & 0.00331 \\
\hline Religion & Mujer & 7.5 & 5.5 & 21.5 & 225 & 32.6 & 330 & 18.8 & 18.4 & 19.6 & 20.6 & 0.04280 & 0.66763 \\
\hline \multirow{2}{*}{$\begin{array}{l}\text { Temor al } \\
\text { qué dirán }\end{array}$} & Varón & 21.0 & 26.4 & 31.7 & 34.4 & 20.4 & 110 & 12.8 & 11.4 & 140 & 16.9 & 0.14134 & 0.00003 \\
\hline & Mujer & 5.3 & 2.7 & 10.8 & 9.8 & 22.8 & 228 & 22.5 & 25.9 & 38.6 & 38.8 & 0.07558 & 0.11635 \\
\hline \multirow{2}{*}{$\begin{array}{l}\text { Impukso } \\
\text { sexual }\end{array}$} & Varón & 2.2 & 1.3 & 5.7 & 4.3 & 26.6 & 179 & 30.9 & 32.6 & 346 & 43.9 & 0.12794 & 0.00029 \\
\hline & Mujer & 2.0 & 1.6 & 15.8 & 205 & 38.1 & 378 & 22.1 & 19.6 & 220 & 20.5 & 0.06460 & 024824 \\
\hline \multirow{4}{*}{$\begin{array}{l}\text { Educación } \\
\text { sexual en } \\
\text { el colegio } \\
\text { Amistades }\end{array}$} & Varón & 8.5 & 7.2 & 24.1 & 269 & 22.6 & 28.4 & 15.8 & 16.3 & 290 & 21.2 & 0.10292 & 0.00825 \\
\hline & Mujer & 4.0 & 3.0 & 17.5 & 17.7 & 30.1 & 248 & 19.8 & 22.5 & 28.6 & 32.0 & 0.07100 & 0.16299 \\
\hline & Varón & 3.7 & 1.6 & 13.0 & 10.7 & 30.4 & 18.7 & 24.6 & 27.5 & 28.3 & 41.5 & 0.18039 & 0.00000 \\
\hline & Mujer & 2.5 & 1.6 & 11.8 & 15.9 & 31.3 & 310 & 24.3 & 22.5 & 30.1 & 29.0 & 0.06381 & 026049 \\
\hline \multirow{2}{*}{$\begin{array}{l}\text { Curiosidad } \\
\text { sexual }\end{array}$} & Varón & 1.0 & 0.9 & 7.1 & 5.2 & 25.8 & 17.1 & 28.0 & 31.6 & 38.1 & 45.2 & 0.12047 & 0.00086 \\
\hline & Mujer & 1.0 & 1.9 & 15.5 & 200 & 31.8 & 35.7 & 22.8 & 22.3 & 290 & 20.0 & 0.11637 & 0.00152 \\
\hline \multirow{2}{*}{$\begin{array}{l}\text { Peligro } \\
\text { del sida }\end{array}$} & Varón & 1.6 & 3.4 & 6.7 & 189 & 16.0 & 26.4 & 19.1 & 20.6 & 56.6 & 30.7 & 0.28798 & 0,00000 \\
\hline & Mujer & 2.0 & 0.8 & 6.2 & 4.0 & 15.1 & 112 & 18.0 & 26.1 & 58.7 & 57.9 & 0.12481 & 0.00046 \\
\hline \multirow{3}{*}{ Autocontrol } & Varón & 3.9 & 8.3 & 13.6 & 305 & 25.5 & 26.1 & 23.1 & 13.8 & 339 & 21.3 & 0.25692 & 0.00000 \\
\hline & Mujer & 2.0 & 1.3 & 8.6 & 6.3 & 24.0 & 239 & 24.3 & 26.4 & 41.1 & 42.1 & 0.05499 & 0.41749 \\
\hline & Varón & 2.5 & 3.2 & 11.3 & 130 & 26.6 & 235 & 26.6 & 23.8 & 329 & 36.6 & 0.06073 & 0.31103 \\
\hline Dcasión & Mujer & 3.3 & 3.4 & 17.4 & 21.7 & 35.1 & 30.4 & 18.3 & 18.4 & 26.1 & 25.9 & 0.06213 & 028738 \\
\hline
\end{tabular}

Estos resultados significan que varones y mujeres están de acuerdo en valorar de modo elevado el rol de la figura paterna en la sexualidad del varón, pero, en lo que atañe a la sexualidad de la mujer, puede observarse que la significancia atribuida a la figura del padre es mucho menor.

La religión, por su parte, es vista como una fuerza de poco peso en la conducta y actitudes sexuales del varón. Hombres y mujeres le conceden poco significado en la sexualidad masculina (pero de todos modos el $23 \%$ de hombres cree que es significativa al escoger las alternati- vas bastante y muy importante, vs. el $17 \%$ de mujeres; $\mathrm{p}<0.00331$ ). Para las actitudes y conducta sexuales femeninas, sin embargo, el significado atribuido a la religión es mayor $(38,4 \%$ de varones y $39 \%$ de mujeres seleccionaron las posibilidades bastante y muy importante).

En general, los porcentajes revelan que las personas son del parecer que las creencias religiosas no influyen en la sexualidad de las personas. Pero, si bien la religión ha perdido mucha de la fuerza que tuvo en el pasado, ella es vista todavía por uno de cada tres encuestados como una variable de signi- 
ficado en las actitudes y conductas sexuales femeninas.

Los porcentajes indican que en la percepción de los encuestados el temor al qué dirán no posee mucho peso en la sexualidad masculina $(26,8 \%$ de varones y $28,3 \%$ de mujeres escogen las alternativas bastante y muy importante), aun cuando el $20,4 \%$ de varones le reconoce cierto significado a través de su elección por la alternativa regular $(p<0.00003)$. Sin embargo, no sucede lo mismo con la sexualidad femenina: $64,7 \%$ de las mujeres y $61,1 \%$ de los hombres consideran que la influencia del temor al qué dirán es en el caso de ellas bastante y muy importante. Es decir: las mujeres son vistas como más sensibles a la presión social en el terreno de la sexualidad.

Al tratar del impulso sexual se registran diferencias: $76,5 \%$ de las mujeres consideran que es decisivo para el varón (bastante y muy importante) $\mathrm{y}$ $65,5 \%$ de varones opta por lo mismo $(\mathrm{p}<0.00029)$, pero unos y otras están de acuerdo en concederle menos significado en las mujeres $(44,1 \%$ de varones y $40,1 \%$ de mujeres optan por las alternativas antes mencionadas).

Nótese el hecho de que las mujeres consideran a esta variable, de naturaleza biológica, como más significativa en la conducta y actitudes sexuales de los varones de lo que los propios hombres lo hacen.

El valor que concede la muestra a la influencia de la educación sexual en los colegios es más bien relativo: $37,5 \%$ de las mujeres le dan bastante y mucha importancia en el caso del varón, $\mathrm{y}$ $44,8 \%$ de los varones hacen lo mismo $(p<0.00825)$. Sin embargo, uno y otro sexo dan más peso a la educación sexual en la mujer $(54,5 \%$ de mujeres y $48,4 \%$ de varones optan por considerarle bastante y muy importante).

Resulta evidente el escepticismo de los encuestados respecto de la influencia de la educación sexual, sobre todo para regular la sexualidad de los varones.

¿Qué ocurre en el caso de las amistades? El 69\% de mujeres cree que son decisivas (bastante y muy importante) para las actitudes y conductas sexuales del varón vs. $52,9 \%$ de varones del mismo parecer $(p<0.00000)$. En el caso de la influencia de las amistades en la mujer, $51,5 \%$ de mujeres y $54,4 \%$ de varones le conceden gran valor (bastante y muy importante). Esto es: mientras hombres y mujeres conceden, en porcentajes parecidos, igual importancia a los amigos en el caso de las mujeres, éstas perciben a los amigos del varón como de gran significado.

En lo que atañe a la curiosidad sexual, hombres y mujeres le conceden gran valor en la sexualidad masculina: $76,8 \%$ de las mujeres y $66,1 \%$ de varones la consideran bastante y muy importante $(\mathrm{p}<0.00086)$. Los porcentajes son mucho menores en la valoración de lo que ocurre con la mujer, en cuyo caso, además, la tendencia es inversa: $42,3 \%$ de las mujeres y $51 \%$ de los varones le dan gran importancia. 
El peligro del sida sí es percibido como una variable de gran significado. El $51,3 \%$ de mujeres y $75,7 \%$ de varones lo consideran bastante y muy importante en la sexualidad masculina $(\mathrm{p}<0.00000)$. En la sexualidad de la mujer el peligro del sida aparece aun como más significativo: $84 \%$ de mujeres y $76,7 \%$ optan por las alternativas antes mencionadas $(\mathrm{p}<0.00046)$.

Con respecto al autocontrol, 35,1\% de mujeres y $57 \%$ de varones lo consideran bastante y muy importante en la sexualidad masculina $(\mathrm{p}<0.00000)$, pero en el caso de la femenina los porcentajes son casi semejantes $(68,5 \%$ de mujeres y $65,4 \%$ de varones). Obsérvese acá que las mujeres son escépticas acerca de la capacidad de autocontrolarse por parte de los varones, pero sí se ven ellas como responsables de su sexualidad.
Con respecto a "la ocasión" $60,4 \%$ de mujeres y $59,5 \%$ de varones le conceden bastante y mucha importancia en la sexualidad del varón. Pero en el caso de la mujer estos porcentajes disminuyen: $44,3 \%$ de mujeres y $44,4 \%$ de varones son del mismo parecer.

\section{VALORACIÓN DE LA FUERZA DEL}

\section{IMPULSO SEXUAL POR REGIONES}

La tabla $\mathrm{N}^{\circ} 5$ presenta los porcentajes de hombres y mujeres que atribuyen cada una de las cinco posibilidades a la sexualidad de hombres y mujeres de la costa, la sierra y la selva.

La fuerza del impulso sexual en el hombre y la mujer de la costa es vista por la inmensa mayoría como de una intensidad normal. Pero a los hombres costeños se les suele atribuir, en mayor porcentaje que a las mujeres, una inten-

Tabla $\mathrm{N}^{\circ} 5$

Valoración de la fuerza del impulso sexual en las personas de las tres regiones del Perú

\begin{tabular}{|c|c|c|c|c|c|c|c|c|c|c|c|c|c|}
\hline \multirow[b]{2}{*}{ Regui } & & \multicolumn{2}{|c|}{ Un 배비 } & \multicolumn{2}{|c|}{ DetuI } & \multicolumn{2}{|c|}{$\begin{array}{l}\text { loteigutad } \\
\text { Namal }\end{array}$} & \multicolumn{2}{|c|}{ Fiert } & \multicolumn{2}{|c|}{ Uny fiert } & \multirow[b]{2}{*}{$y$} & \multirow[b]{2}{*}{ HS } \\
\hline & & H & u & H & u & $\mathrm{H}$ & u & $\mathrm{H}$ & u & H & u & & \\
\hline & Hembere & $1 \mathrm{~B}$ & 1.2 & 82 & 69 & 12.9 & 15.1 & 286 & 28.8 & 185 & 11.4 & QDE14 & D6EOE \\
\hline \multirow{2}{*}{ cant } & Wuler & 13 & 1.1 & 6.1 & $6 \mathrm{~B}$ & 60.2 & 田2 & $18 \mathrm{~B}$ & 15.1 & 130 & 65 & $0.12 \mathbf{2} 19$ & 口四酯"- \\
\hline & Hombre & 15 & 1.9 & 133 & 85 & 16.8 & 152 & 218 & 21.1 & 165 & 11.1 & 口0958 & $803113^{\circ}$ \\
\hline \multirow[t]{2}{*}{ ste me } & Mnjer & 20 & $\mathbf{3 . 3}$ & $12 \mathrm{~B}$ & $11 \mathrm{~B}$ & 18.4 & 195 & 210 & 20.9 & $15 \mathrm{~B}$ & 11.4 & 16ו18ם & 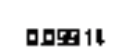 \\
\hline & Hambere & Q & 1.4 & $\mathbf{3 B}$ & 39 & 29.0 & - 5 & 213 & 21.1 & $\mathbf{3 . 1}$ & 115 & 201502 & 06251 \\
\hline Sye wa & Moler & 10 & 1.6 & $\mathbf{3 5}$ & 30 & 26.3 & 5.4 & 228 & 25.1 & 56.4 & 13.4 & Q & Q.131日 \\
\hline
\end{tabular}


sidad fuerte y muy fuerte: $47,1 \%$ de varones optan por esas dos alternativas al momento de evaluar el impulso sexual del hombre costeño, en tanto que $31,8 \%$ de ellos opta por ellas en lo que se refiere a la sexualidad de la mujer costeña. También las mujeres valoran como fuerte y muy fuerte la intensidad de la sexualidad del hombre costeño $(46,2 \%, v s .22,3 \%$ que optan por fuerte y muy fuerte en la evaluación de la sexualidad femenina costeña).

Como ya se mencionó, varones y mujeres concuerdan en la valoración del impulso sexual del varón costeño como normal (42,9\% vs. 45,7\%, respectivamente). La tendencia a valorar la fuerza de la sexualidad como normal en la mujer costeña es marcada aunque con diferencias $(60,2 \%$ de los varones y $69,2 \%$ de las mujeres), que disminuyen en lo que se refiere a la alternativa fuerte $(18,8 \%$ de varones y $15,7 \%$ de mujeres) pero que una vez más se vuelven mayores en lo que se refiere a la alternativa muy fuerte $(13 \%$ de varones $v s$. $6,6 \%$ de mujeres).

Sin embargo, la suma de las alternativas fuerte y muy fuerte en la valoración del impulso sexual de la mujer costeña arroja diferencias dignas de ser tomadas en cuenta: $31,8 \%$ de varones opta por ellas, pero sólo $22,3 \%$ de mujeres es del mismo parecer $(\mathrm{p}<0.00058)$. Es decir, las mujeres consideran la sexualidad femenina costeña en general como menos fuerte de lo que lo hacen los varones.
En lo que atañe al habitante de la sierra se observa también que la fuerza del impulso sexual es considerada normal por casi la mitad de los encuestados, tanto si ese habitante es hombre $(\mathrm{H}$ : $46,8 \%$; M: 45,2\%), como si es mujer (H: 48,4\%; M: 49,6\%).

En el caso del hombre andino, al considerar las alternativas fuerte y muy fuerte ocurre lo contrario de lo sucedido con la mujer costeña: las mujeres optan por esas alternativas con mayor frecuencia $(45,2 \%)$ que los varones $(38,4 \% ; \mathrm{p}<0.0313)$.

Hombres y mujeres arrojan porcentajes relativamente semejantes en lo que se refiere a las alternativas fuerte y muy fuerte al momento de valorar el impulso sexual de la mujer serrana: $36,8 \%$ y $32,2 \%$, respectivamente.

Con respecto al hombre y la mujer costeños y andinos, el habitante de la selva, de uno y otro sexo, aparece como aquel que tiene el impulso sexual más fuerte: mientras que sólo $29 \%$ de varones y $25,9 \%$ de mujeres considera dicho impulso como normal en el hombre de la selva, $67 \%$ de varones y $68,7 \%$ de mujeres optan por las alternativas fuerte y muy fuerte. Estos porcentajes se hacen todavía más elevados en lo que se refiere al impulso sexual de la mujer de la selva: $69,2 \%$ y $70,1 \%$ de mujeres lo consideran fuerte y muy fuerte. 
Percepción de la opinión social frente a las relaciones sexuales antes del matrimonio

Dos ítems de nuestro reactivo evaluaron cómo creían los integrantes de la muestra que la sociedad peruana en general valoraba el que un hombre/una mujer hubieran tenido relaciones sexuales antes del matrimonio. Se trata, como sabemos, de un tema decisivo en la discusión acerca de la sexualidad en la sociedad peruana.

Como podrá observarse en el gráfico $\mathrm{N}^{\circ} 11$, hombres y mujeres creen que la sociedad peruana no tiene una opinión definida acerca de las relaciones sexuales prematrimoniales de los varones.

Destaca, sin embargo, que $20 \%$ de las mujeres cree que la sociedad tiene una opinión muy positiva de las relaciones sexuales prematrimoniales en los varones.

Gráfico № 11

Valoración que la sociedad peruana hace de las relaciones sexuales antes del matrimonio en los varones

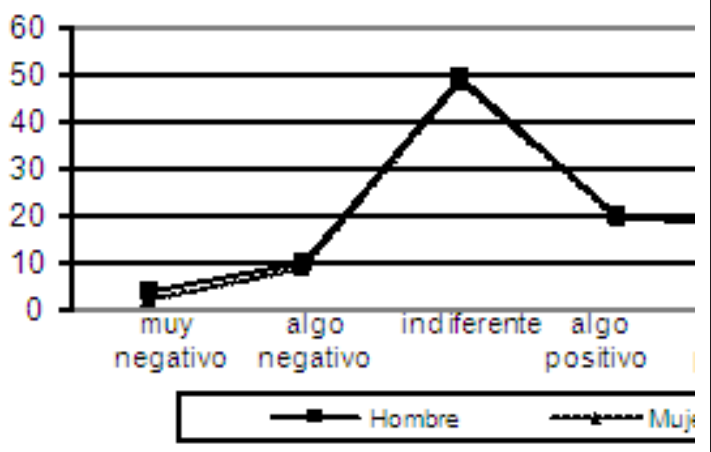

Gráfico № 12

Valoración que la sociedad peruana hace de las relaciones sexuales antes del matrimonio en las mujeres

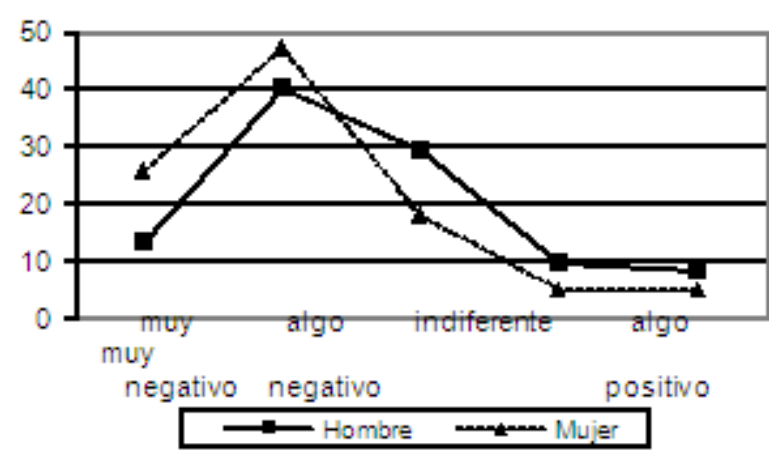

En el gráfico $\mathrm{N}^{\circ} 12$ hallamos que la percepción de la opinión de la sociedad peruana acerca de relaciones sexuales prematrimoniales en las mujeres es percibida en general como negativa. En efecto, $53,4 \%$ de varones y $72,7 \%$ de mujeres son de ese parecer (alternativas muy negativo y algo negativo). Obsérvese el porcentaje mucho mayor de mujeres $(\mathrm{p}<0.00000)$.

\section{DisCusión}

En los resultados destaca, en primer lugar, la valoración diferencial que hacen hombres y mujeres de la importancia de la dimensión sexual en sus respectivos sexos. Unos y otros reconocen que la sexualidad posee gran importancia para el ser humano (reconocimiento que desde Freud se ha ido extendiendo y que hoy es admitido por cualquier 
texto de salud mental); pero, unos y otros creen que la sexualidad posee diferente fuerza y significado según se trate de personas del sexo masculino o del sexo femenino (la sexualidad en el varón tiene mayor fuerza y es más determinante en su conducta que la sexualidad en la conducta de la mujer).

Este hallazgo repite lo encontrado en estudios previos en nuestro medio, así como en la literatura internacional (Eysenck, 1978; Wilson, 1978; Zuckerman et al., 1976). En el Perú, León y Cossío de Preciado (1993) pidieron a 707 universitarios (400 varones y 307 mujeres) que evaluaran la fuerza de su impulso sexual en una escala de 0 a 10 y encontraron que la media para los varones fue de 7 , mientras que para las mujeres era de 5. Cuatro años después León y Puga Vásquez (1997) plantearon la misma interrogante a 1.043 universitarios (446 varones y 697 mujeres), en una escala de 1 a 10: el promedio de la autovaloración de la fuerza del impulso sexual entre los varones fue 7.34; y el de las mujeres 6.08 $(\mathrm{p}<0.05)$.

Como hemos dicho, esta suposición es compartida por todos los estudiantes indistintamente de su género. Así, los hombres afirman no sólo tener un impulso sexual fuerte, sino que atribuyen menor fuerza al de las mujeres; ellos afirman hablar del sexo y pensar en él más que las mujeres, quienes igualmente creen que los varones conversan y piensan más que ellas acerca de temas sexuales.
Afirmar la sexualidad, expresarla, experimentar con ella, dar a conocer a otros 'logros' (reales o imaginarios) y, a la vez, ganar de modo vicario destrezas y técnicas por medio de lo que otros informan: todo esto se desprende como característico del varón, de acuerdo con lo que hemos hallado.

Puede reconocerse la existencia de normas diferentes, vinculadas con la ideología machista. Esto se expresa de modo claro en la percepción que los encuestados tienen de la actitud de la sociedad frente a las relaciones sexuales prematrimoniales de hombres y mujeres. Como puede verse, de acuerdo con lo que piensan los sujetos de la muestra, la sociedad peruana tiene una actitud de indiferencia (cuando no de benevolencia) respecto de las relaciones sexuales prematrimoniales en los varones, pero rechaza las de las mujeres, evidenciando de ese modo el valor que concede a la virginidad en éstas.

Más todavía: teniendo en cuenta el porcentaje de sujetos que cree que la sociedad ve con buenos ojos las experiencias sexuales prematrimoniales de los varones, es probable que, como lo señala Giddens (1998), éstas, en el caso de los muchachos, sean vistas como un plus, casi como una ganancia.

¿En qué consiste ese plus? En nuestro medio, La Rosa (1997) da la respuesta al indicar que se espera que en la relación hombre-mujer el primero sea el experto sexual. En el caso de la mujer, 
señala la autora, se espera que "no exprese deseo sexual y sea iniciada por el hombre que ama, con quien se vincula en matrimonio y del que aprende el comportamiento sexual" (p. 54).

En su obra Sobre héroes y batallas, Callirgos (1996) señala que en las culturas latinoamericanas predomina la imagen del hombre llevado por sus instintos y de la mujer como alguien que pone límites, lo cual encaja con la idea de que la sexualidad masculina es de mayor intensidad que la femenina, $y$ explica, además, por qué se tolera más que el varón tenga relaciones sexuales prematrimoniales.

De allí la gran importancia que se atribuye al autocontrol entre las mujeres. En las tablas 2 y 3 podrá reconocerse cuán diferente es la valoración que hacen los encuestados de la importancia del autocontrol para los varones y para las mujeres. Mientras que para los primeros el autocontrol aparece en los últimos lugares, para las mujeres se encuentra en la tercera ubicación, después del peligro del sida y de la madre.

Cabe, por cierto, preguntarse qué pudieron entender las personas bajo el término autocontrol. Regular el comportamiento, no ceder a 'tentaciones', 'mantener distancias' ('darse su lado'), no manifestar de modo expreso interés por otra persona del sexo opuesto, tener un comportamiento decente: éstos son algunos de los sentidos del término.

Recato, prudencia, una cierta pasividad en las relaciones sociales, son los rasgos que deben distinguir a la mujer. "A la mujer se le enseña desde niña a controlar su temperamento, porque será necesario cuando en el futuro sea madre. Por eso las mujeres se sienten culpables por sus expresiones de furia", escribe una especialista en el estudio de géneros (Yanaylle García, 1996, p. 77).

Ese comportamiento refuerza la imagen social de la adolescente o joven como una 'muchacha decente' $y$, al mismo tiempo, controla los eventuales avances de personas del sexo masculino que podrían llevar a relaciones sexuales previas al matrimonio.

Éstas, a su vez, acarrean para las mujeres el peligro de un embarazo no deseado. Cuando esto ocurre en la adolescencia, las consecuencias sociales son muy negativas. Farías (1997) señala que "la adolescente embarazada es la antítesis de la 'niña', ha perdido su inocencia, ha alterado el camino tradicional hacia la conformación de la familia", transformándose en una paria (p. 290). Esto provoca más angustia por parte de las mujeres, que son más conscientes del riesgo de embarazo como resultado de relaciones sexuales previas al matrimonio (Baldwin \& Baldwin, 1997).

Ahora bien, ésta es una forma de explicar las causas del menor interés de las mujeres por la sexualidad. Pero no se trata del único modo de entender las cosas. 
Allí están los planteamientos de Eysenck (1978), quien entiende las diferencias en actitudes y conductas sexuales entre varones y mujeres como resultado de la presencia de factores constitucionales de personalidad (algo ya observado por Schofield, 1968; Giese \& Schmidt, 1968; y Husted \& Edwards, 1976). Es decir, los hombres poseerían una 'libido más alta' que las mujeres. Wilson, un colaborador de Eysenck, ha señalado que la más 'alta libido' de los varones se refiere al deseo de variedad de parejas y actividades más que una frecuencia preferida de relaciones con la misma persona (Wilson, 1989).

Sea como fuere, lo efectivo es que las mujeres parecen reconocer con más dificultad su sexualidad que los varones. En su investigación, León y Cossío de Preciado (1993) encontraron que las mujeres afirmaban pensar menos en el sexo que los varones y tener posiciones más conservadoras en materia de sexo. De hecho, ellas se iniciaban sexualmente en una edad más avanzada que los varones y muchas afirmaban no haber tenido jamás relaciones sexuales.

De ser efectivo esto, la sexualidad continuaría siendo para muchas mujeres de clase media un tema incómodo, rodeado de incógnitas, incertidumbres y hasta peligros. Entre los varones, por el contrario, predominan actitudes y conductas sexuales más abiertas y autoafirmativas.

Nos referiremos ahora a los resultados obtenidos en la valoración de la fuerza del impulso sexual en los costeños, serranos y selváticos.

En la realidad cotidiana del Perú, circulan muchas afirmaciones acerca de los modos de ser de los habitantes de las tres regiones clásicas del país. Una de ellas tiene que ver con la sexualidad, que en el caso de la persona de la selva suele ser considerada como de mayor intensidad. Los resultados obtenidos expresan ese estereotipo. El hombre y la mujer selváticos son vistos como poseedores de una sexualidad mucho mayor que la de los costeños y serranos.

Ahora bien, ¿qué lectura deberíamos dar a estos resultados a contraluz de la realidad social del Perú?

En los últimos años se ha producido un proceso de reversión de la imagen social del costeño, del serrano y del selvático. Mientras que históricamente el habitante de la sierra fue visto como retrógrado, pasivo, carente de iniciativa (Prado, 1941; García Calderón, 1907; una perspectiva amplia es dada por Sanders, 1997), el proceso de migración interna ha modificado esa percepción, transformando a Lima en una ciudad de todas las sangres y en el escenario del despliegue de capacidades de trabajo, inventivas y esfuerzos por parte de los migrantes de la sierra, de tal magnitud que ha provocado el interés de los investigadores de las ciencias sociales (Adams \&Valdivia, 1991).

Esto ha traído como consecuencia una revalorización (no exenta de ambivalencias, es cierto) del habitante de la 
sierra. En un trabajo efectuado por uno de nosotros (León, 1998) la imagen social más positiva fue la del serrano, visto como trabajador, esforzado, discreto, etc. Tanto el costeño como el selvático son percibidos como poco afectos al trabajo, dicharacheros, marcadamente sociales.

Analizando estas características, podríamos decir que el habitante de la sierra es visto como alguien caracterizado por valores de marcado autocontrol y disciplina, que también se extenderían al terreno sexual. Costeños y selváticos son, más bien, de una sociabilidad algo desbordada, expresada en relaciones sociales de fácil curso y repetida frecuencia, en las cuales virilidad, feminidad, coquetería, poseen gran valor.

Es importante recordar acá que estamos hablando de estereotipos, porque no parece plenamente justificado extender el autocontrol y la disciplina atribuidos al habitante de la sierra a su sexualidad. Alguna información fáctica apunta más bien en la dirección contraria. Cáceres Palacios (1998), en un reciente estudio comparativo entre Chiclayo, Cusco e Iquitos, encontró que el $27 \%$ de varones cusqueños respondió afirmativamente a la pregunta de si alguna vez habían dejado embarazada a una mujer de modo no planificado (vs. 16,1\% de varones chiclayanos y $23 \%$ de iquiteños). El mismo investigador halló que el aborto como forma de resolución del embarazo fue más reportada por ellos ( $43 \%$ vs. $36 \%$ entre chiclayanos y $39 \%$, por parte de los iquiteños).

Asimismo, está el hecho de la prole numerosa, frecuente entre la población serrana. Montoya (1998) señala que en la cultura indígena "hombres y mujeres, niños y niñas son hábiles para el trabajo, y por esa habilidad constituyen un recurso que define la noción quechua de riqueza" (p. 91). En ella, como en otros contextos campesinos, la mujer es vista ante todo como productora de hijos (Macfarlane, 1993).

Volvamos, sin embargo, a los estereotipos sexuales de costeños y selváticos, vistos como mucho más sociables que los serranos.

Sociabilidad y sexualidad, oralidad y erotismo: he aquí dos binomios que valdría la pena explorar en trabajos posteriores. Un observador perspicaz de nuestra realidad podrá reconocer una tendencia a lo que, a falta de un nombre mejor, llamaremos la erotización de la vida de relación entre nosotros. Relaciones amistosas entre mujeres y hombres suelen ser consideradas como virtualmente imposibles, pues se cree que en toda relación entre uno y otro sexo el componente erótico está presente. El marcado machismo, la no menos profunda preocupación por la virginidad y por la virilidad; y el contexto represivo de la sexualidad que caracterizan todavía a nuestra sociedad, contribuyen a esa erotización, que se expresa por ejemplo en los muchos chistes sexuales que se registran en el Perú (Ahlborn, 1988). 
La mujer de la selva constituye la más clara expresión de esa erotización, según los estereotipos predominantes. Impresiones no sistematizadas pero muy frecuentes permiten afirmar que ella es vista como apasionada, inquieta, seductora, con cierta proclividad a la promiscuidad, y muy fértil. Se asocia esto a explicaciones vagas referidas al clima, la atmósfera, e, inclusive, a factores alimenticios (recuérdese que algunos productos provenientes de la selva son vistos como potenciadores de la sexualidad).

La selva es, para muchos peruanos, lo ignoto, lo misterioso. Es frecuente escuchar en reuniones académicas o en programas periodísticos que hay en esa región zonas casi vírgenes, y etnias que recién comienzan a integrarse al país. Animales de suma peligrosidad (boas, pirañas), riquezas aparentemente al alcance de la mano pero cuyo acceso entraña riesgos mortales; condiciones duras de vida, prácticas curanderiles exóticas: ésta fue la imagen de la selva por mucho tiempo. En cierta medida eso prosigue: en un reciente estudio acerca de creencias y opiniones sobre el daño en universitarios de Chiclayo y Lima, el autor (Palomino, 1998) encontró que para los capitalinos de uno y otro sexo, los departamentos en los que se hacía más daño eran Loreto y Amazonas, seguidos por Piura.

Esta imagen de escaso desarrollo, de primacía de condiciones entre naturales y primitivas no es, por cierto, algo creado por el imaginario popular. En la clasificación llevada a cabo por Sinesio López (1997) de los departamentos del Perú según su nivel de modernización, sólo Madre de Dios se ubica en el nivel medio, mientras que Ucayali, Loreto y San Martín se encuentran en el bajo; y Amazonas, inclusive, en el muy bajo.

Esta temática, como hemos dicho, es fascinante y permanece aún inexplorada. Las explicaciones que se pueden dar sobre el particular sólo tienen un carácter tentativo, en la medida en que carecemos de datos 'duros' provenientes de investigaciones. Señalemos solamente que lo 'primitivo', lo menos desarrollado, lo 'natural' (y la selva es todavía eso en el contexto de la realidad peruana) es por lo general asociado a una sexualidad poco controlada, incitante, que despierta la curiosidad y el deseo de los demás.

Se trata, como decimos, de estereotipos. Pero resulta claro que los estereotipos tienen que encontrar algún sustento en la realidad. Aunque son estadísticas algo antiguas, las consignadas por Ferrando et al. (1989) en su libro Adolescentes de hoy, padres del mañana: Perú, merecen ser mencionadas. Al tratar sobre el matrimonio y la natalidad entre nosotros, las autoras señalan que para las mujeres, según el censo de 1981, "la edad promedio a la primera unión matrimonial era más alta en Lima y Callao (24 años) y más baja en los departamentos selváticos de Amazonas, Madre de Dios, San Martín y Uca- 
yali (alrededor de 20 años)" (p. 34). Asimismo, al comentar que el $28 \%$ de mujeres entre 20 y 29 años tuvo relaciones sexuales prematrimoniales antes de los 20 años, anotan que "el porcentaje va del 25 por ciento en zonas urbanas al 34 por ciento en áreas rurales", siendo el nivel más alto en la selva (43\%) (p. 41).

Por su parte, Alarcón y Gonzales (1994), en su estudio sobre el comportamiento sexual de varones en Lima, Cusco e Iquitos, encontraron que la actividad sexual de ellos era más frecuente en Iquitos $(72,1 \%)$ que en Cusco (47\%) y en Lima (34\%). No sólo eso: la frecuencia de la actividad sexual reportada fue mucho mayor entre los varones de Iquitos (2-4 veces al mes: $62 \%)$, que entre los limeños (0-1 vez al mes: $82,4 \%$ ) y los cusqueños ( 0 1 vez al mes: $84 \%$ ).

De otro lado, Salaverry y González (1994) hacen referencia al hecho de que el embarazo en la adolescencia es culturalmente aceptado en la selva, en el ejemplo de Pucallpa, "tal es así que cerca del $60 \%$ de las madres adolescentes en Pucallpa deseaban tener el hijo durante la adolescencia, que contrasta con lo que ocurre en Lima, donde tan sólo el 25\% desea tener el hijo".

Analicemos ahora la importancia atribuida a las variables en la sexualidad del hombre y de la mujer.

Es interesante anotar en el caso de los varones (tabla $\mathrm{N}^{\circ} 2$ ), que éstos consideran de gran significado el peligro del sida (algo que, de acuerdo con las mujeres, no parece ser tan importante para ellos), lo que podría ser entendido tanto como un indicador de éxito de los programas de prevención entre nosotros, pero también como una conciencia mayor del grado en el cual esa epidemia se ha difundido.

Pero si bien los hombres y mujeres difieren en el valor concedido al sida en la sexualidad masculina, ambos están en pleno acuerdo en que la curiosidad y el impulso sexuales son decisivos en la sexualidad del varón. Incluso puede observarse que las mujeres conceden a estos dos factores más peso que los propios varones.

Lo anteriormente expuesto, ¿qué implicancias tiene para los programas de educación sexual?

En primer lugar, repite los resultados de otras investigaciones que informan sobre una sexualidad más intensa en los varones. Una sexualidad que en el caso de los varones peruanos, al parecer no consigue integrarse con una relación de afecto. Aunque recientes estudios demuestran que la iniciación sexual en el caso de los varones es cada día más con una persona por la cual se siente amor, amistad o atracción (Valdez et al., 1991), es asimismo cierto que el porcentaje de iniciaciones sexuales con prostitutas o determinadas por la ocasión continúa siendo elevada.

Así, creemos que el énfasis en la integración de la sexualidad con el afecto debe ser mayor en el caso de los varo- 
nes. Baldwin y Baldwin (1997) han tratado en detalle las razones por las que la actividad sexual de los varones suele permanecer desvinculada del área afectiva, refiriendo sus planteamientos a los adolescentes norteamericanos. Sus reflexiones, sin embargo, tienen vigencia para nuestro medio. Esto tiene como corolario casi lógico el que en los programas de educación sexual se exploren y discutan de modo claro elementos ideológicos propios del machismo, que es, en el fondo, el principal basamento para conductas sexuales masculinas como las antes descritas.

La insistencia en esto nos parece necesaria desde otro punto de vista. El conocimiento de los órganos sexuales y de las reacciones corporales vinculadas a la sexualidad es mucho mayor en los varones adolescentes que entre las mujeres en la misma etapa. Pero como contraparte, la esfera de los afectos les es desconocida.

Esto no es, sin embargo, la única conclusión que se desprende de nuestro trabajo. Tenemos también la relativización del papel de la religión. Si bien no se ha tratado de modo específico y detenido a la religión como fuerza reguladora de la sexualidad, el hecho de que ella ocupe el último lugar tanto para hombres como para mujeres en su rol de influencia en las actitudes y conductas sexuales, parece evidencia de su escaso significado. En el Janus report on sexual behavior, Janus y Janus (1993), trabajando entre 1983 y 1992 con 1.372 varones y 1.418 mujeres, no encontraron diferencias en la conducta sexual entre personas con creencias religiosas y personas sin ellas. Por su parte, un informe periodístico reciente destaca que las muchachas católicas alemanas entre 14 y 17 años de edad eran inclusive más activas sexualmente pero menos informadas que las de otras confesiones (0tt, 1999).

Esto no significa que la religión haya dejado de ser significativa: su importancia se conserva en el plano de la ética, mientras que la sexualidad ha quedado al margen de ella. Pareciera más bien que en el dominio de la sexualidad se ha impuesto lo que Alberoni (1997) ha llamado el rechazo del concepto de pecado y de culpa.

De otro lado, el matrimonio, la institución que la religión católica sanciona como la única forma de ejercicio de la sexualidad libre del pecado, ha entrado también en lo que podríamos llamar una época de revisión (Del Castillo, 1996), lo cual ha redundado en una menor consideración de los parámetros religiosos.

Por todo esto, vincular la educación sexual a la religión no llevaría a ningún logro efectivo de los objetivos que la primera se propone.

Sí es importante, de otro lado, la percepción que hombres y mujeres tienen de que el impulso y la curiosidad sexuales son los factores de mayor fuerza en la sexualidad masculina. La insis- 
tencia en el análisis y la discusión de ellos entre los adolescentes varones es la conclusión lógica de este hallazgo. Estudiarlos, analizarlos, discutirlos, permitirá al joven entenderlos, aceptarlos y, consecuentemente, tener mayores posibilidades de integrarlos en una perspectiva sana de su sexualidad.

Esta es una meta muy ambiciosa, que parece estar fuera del alcance de la educación sexual. Ésta, transmitida por horas y ocasiones en la escuela, por personas de relativo significado emocional para los estudiantes, no puede reemplazar lo que la educación del hogar, repetida, permanente e integrada a la realidad afectiva del niño y el adolescente, debe implantar.

Por último, destaca el temor al sida. Nuestros resultados permiten afirmar que la conciencia de la posibilidad de contraer el sida es elevada. Esta conciencia parece mayor entre los muchachos, y es un factor muy favorable para lograr resultados de verdad efectivos.

Ahora bien, no es a través del temor como se logran cambios duraderos en la conducta de las personas. Se trata más bien de desarrollar una estrategia multimodal, que abarque las más diversas esferas de la vida de la persona, y que actúe sobre ella desde muy temprano (Anicama, 1998). Creemos que la información contenida en este trabajo puede ser de algún valor para el desarrollo de tal estrategia.

\section{REFERENCIAS}

Adams, N. \& Valdivia, N. (1991). Los otros empresarios. Ética de migrantes y formación de empresas en Lima. Lima: Instituto de Estudios Peruanos.

Ahlborn, B. (1988). Picardía criolla. Un estudio psicológico del chiste. Lima: Universo.

Alarcón, I. \& Gonzales, G.F. (1994a). Comportamiento sexual en varones de colegios estatales de Lima, Cusco e Iquitos. En Gonzales, G.F. (Ed.), La adolescencia en el Perú. Lima: Universidad Peruana Cayetano Heredia, 129146.

Alarcón, I. \& Gonzales, G.F. (1994b). Adolescencia y reproducción: comportamiento sexual, conocimiento y uso de métodos anticonceptivos. En Gonzales, G.F. (Ed.), La adolescencia en el Perú, Lima, Universidad Peruana Cayetano Heredia, 147-163.

Alberoni, F. (1997). Las razones del bien y del mal. Barcelona: Gedisa.

Anicama, J. (1998). Psicología, educación y salud mental. Más Luz. Revista Iberoamericana de Psicología y Pedagogía, 4, 249-267.

Atkin, L.C. (1991). El embarazo en la adolescencia en América Latina y el Caribe: causas y consecuencias psicosociales. En Stern, C; Tolbert, K.; Paxman, J.M.; Rizo, A. \& Shepard, B.L., (Eds.), Conferencia internacional sobre fecundidad en adolescentes en América Latina y el Caribe, Memoria, 97-107.

Baldwin, J.D. \& Baldwin, J.I. (1994). Sexual behavior. En Ramachandran, V. S. (Ed.), Encyclopedia of human behavior (vol. 4), San Diego, Academic Press, 159-168. 
Baldwin, J.D. \& Baldwin, J.I. (1997). Gender differences in sexual interest. Archives of Sexual Behavior, 26, 181200.

Becker, M. \& Joseph, J. (1988). Aids and behavioral change to reduce risk: a review. American Journal of Public Health, 78, 395-410.

Ben-Ze'ev, A. (1994). The vindication of gossip. En Goodman, R.F. \& BenZe'ev, A. (Eds), Good gossip. Lawrence: University Press of Kansas, 11-24.

Berenstein, I. (1995). Vínculos y relaciones familiares. En Vidal, G., Alarcón, R.D. \& Lolas Stepcke, F. (Eds.), Enciclopedia iberoamericana de psiquiatría (vol. 2). Buenos Aires: Panamericana, 618-626.

Bergmann, J. (1993). Discret indiscretions. The social organization of gossip. New York: Aldine de Gruyter.

Cáceres Palacios, C. (1998). Sida en el Perú: imágenes de diversidad. Situación y perspectivas de la epidemia en Chiclayo, Cusco e Iquitos. Lima: Universidad Peruana Cayetano Heredia y Redess Jóvenes.

Callirgos, J.C. (1996). Sobre héroes y batallas. Los caminos de la identidad masculina. Lima: Escuela para el Desarrollo-Demus.

Crawford, P. (1994). Sexual knowledge in England, 1500-1750. En Porter, R. \& Teich, M. (Eds.), Sexual knowledge, sexual science. The history of attitudes to sexuality, Cambridge: Cambridge University Press, 82-106.

Chakraborty, R. \& Rowland-Jones, S. (1999). The pathogenesis of HIV disease. Journal of HIV Therapy, 4 (1), 2-8.
Del Castillo, D. (1996). Matrimonio, romanticismo y subjetividad en los años noventa. Quehacer, 101, 72-75.

Eysenck, H.J. (1978). Sex and personality. Londres: Penguin Books.

Eysenck, H.J. \& Wilson, G. (1979). The psychology of sex. Londres: New English Library / Times.

Fagothey, A. (1992). Ética: teoría y aplicación. México, D.F.: McGraw-Hill.

Farías, A. (1997). Sobre educación de la sexualidad. En Grau, D., Delsing, O., Brito, E. \& Farías, A. Discurso, género, poder. Discursos públicos: Chile 1978 1993. Santiago: LOM Ediciones, 271300 .

Fernández, M. (1989). Conocimiento y actitudes sexuales de escolares adolescentes. Evaluación y lineamientos para un programa de educación sexual. Lima: Universidad de Lima \& The Pathfinder Fund.

Fernández, M. (1998). Correlatos afectivos y nivel de conocimientos en el comportamiento sexual de universitarios de Lima. Persona, 1, 119-161.

Fernández-Ríos, L., Cornes, J.M. \& Codesido, F. (1997). Psicología preventiva: situación actual. En Buela-Casal, G., Fernández-Ríos, L. \& Carrasco Giménez, T.J., Psicología preventiva. Avances recientes en técnicas y programas de prevención. Madrid: Pirámide, 59-77.

Ferrando, D., Singh, S. \& Wulf, D. (1989). Adolescentes de hoy, padres del mañana: Perú. New York: The Alan Guttmacher Institute.

Fine, G.A. \& Rosnow, R.L. (1978). Gossip, gossipers, gossiping. Personality and Social Psychology Bulletin, 4, 161-168. 
Fisher, W.A. \& Fisher, J.D. (1993). A general social psychological model for changing AIDS risk behavior. En Pryor, J.B. y Reeder, G.D. (Eds.), The social psychology of HIV infection, Hillsdale, New Jersey; y Hove y Londres: Lawrence Erlbaum, 127-153.

Fuller, N. (1993). Dilemas de la feminidad. Mujeres de clase media en el Perú. Lima: Pontificia Universidad Católica del Perú.

García Calderón, F. (1907). Le Pérou contemporain: étude sociale. Paris: Dujarric.

Giddens, A. (1993). Consecuencias de la modernidad. Madrid: Alianza Editorial.

Giddens, A. (1997). Modernidad e identidad del yo. El yo y la sociedad en la época contemporánea. Barcelona: Península.

Giddens, A. (1998). La transformación de la intimidad. Sexualidad, amor y erotismo en las sociedades modernas. Madrid: Cátedra.

Giese, H. \& Schmidt, A. (1968). Studenten Sexualitaet. Hamburgo: Rowohlt.

Giraldo Neyra, O. (1989). Explorando las sexualidades humanas. Aspectos psicosociales. México, D.F.: Trillas.

Glass-Coffin, B. (1988). El daño, el cuento y el chisme. El poder de la palabra en la medicina tradicional de la costa norte del Perú. En Trabajos del II Congreso Internacional de Medicinas Tradicionales (Área de Antropología Médica). Lima, 157-162.

Goffi, T. (1983). Sexualidad. En De Fiores, S. \& Goffi, S. (Eds.), Nuevo diccionario de espiritualidad. Madrid: Paulinas, 1271-1286.
Howell, J.G. \& Osborn, M.L. (1984). A reference companion to the history of abnormal psychology. Westport, Conn. - Londres: Greenwood Press.

Husted, J.R. \& Edwards, A.E. (1976). Personality correlates of male sexual arousal and behavior. Archives of Sexual Behavior, 7, 149-156.

Jacoby, A. \& Williams, J. (1985). Effects of premarital sexual standards and behavior on dating and marriage desirability. Journal of Marriage and the Family, 45, 1059-1065.

Janus, S.S. \& Janus, C.L. (1993). The Janus Report on Sexual Behavior. New York: Wiley.

Kaplan, H.I., Sadock, B.J. \& Grebb, J.A. (1996). Sinopsis de psiquiatría. Buenos Aires: Editorial Médica Panamericana.

Kinsey, A.C., Pomeroy, W.B. \& Martin, C. E. (1948). Sexual behavior in the human male. Filadelfia: Saunders.

Kinsey, A.C., Pomeroy, W.B., Martin, C. E. \& Gebhard, P.H. (1953). Sexual behavior in the human female. Filadelfia: Saunders.

Kogan, L. (1996). Estudios sobre relaciones de género en los sectores medios y altos de Lima. En Ruiz-Bravo, P., (Ed), Detrás de la puerta. Hombres y mujeres en el Perú de hoy, Lima, Pontificia Universidad Católica del Perú, 27-37.

La Rosa, L. (1997). Adolescencia e iniciación sexual. Lima: Universidad Peruana Cayetano Heredia.

León, F., (Ed.) (1986). Psicología y realidad peruana. Lima: Mosca Azul.

León, R. (1998). El país de los extraños. Lima: Universidad Ricardo Palma. 
León, R. \& Cossío de Preciado, A.M. (1993). Actitudes y comportamientos sexuales en un grupo de estudiantes universitarios de Lima Metropolitana. Revista de Neuro-psiquiatría, 56, 33-58.

León, R. \& Moscoso, S. (1991). Percepción de la envidia en el Perú en un grupo de estudiantes universitarios de Lima Metropolitana. Revista de Neuropsiquiatría, 54, 9-28.

León, R. \& Puga Vásquez, J.L. (1997). Conductas y fantasías sexuales y dimensiones eysenckianas de la personalidad en un grupo de estudiantes universitarios de Lima Metropolitana. Revista de Neuro-psiquiatría, 60, 248-278.

Lersch, Ph. (1968). La estructura de la personalidad. Barcelona: Scientia.

Leventhal, H. \& Clearly, P.D. (1980). The smoking problem: a review of the research and theory in behavioral risk modification. Psychological Bulletin, $88,370-405$.

Linville, P.W., Fischer, G.W. y Fischhoff, B. (1993). AIDS risk perception and perceptions and decision biases. En Pryor, J.B. \& Reeder, G.D. (Eds.), The social psychology of HIV infection, Hillsdale, New Jersey; y Hove y Londres: Lawrence Erlbaum, 5-38.

Loli, A. (sin fecha). La sexualidad en la adolescencia: un estudio peruano. Lima: Servicio Médico Materno Infantil San Alfonso y The Pathfinder Fund.

López Jiménez, S. (1997). Ciudadanos reales e imaginarios. Concepciones, desarrollo y mapas de la ciudadanía en el Perú. Lima: Instituto de Diálogo y Propuestas.
Llor, B., Abad, M.A., García, M. \& Nieto, J. (1998). Ciencias psicosociales aplicadas a la salud. Madrid: McGrawHill-Interamericana.

McCary, J.L. \& McCary, St.P. (1990). Sexualidad humana de McCary. México: D.F.: El Manual Moderno.

Macfarlane, A. (1993). La cultura del capitalismo. México, D.F.: Fondo de Cultura Económica.

Masters, W., Johnson, V. \& Kolodny, R. (1996). Eros. Los mundos de la sexualidad. Barcelona: Grijalbo Mondadori.

Mays, V.M. \& Cochran, S.D. (1988). Issues in the reduction of Aids risk and risk reduction activities by black and Hispanic/Latina women. American Psychologist, 43, 949-957.

Miller, L.C., Bettencourt, B.A., DeBro, Sh. Ch. \& Hoffman, V. (1993). Negotiating safer sex: interpersonal dynamics. En Pryor, J.B. \& Reeder, G.D., (Eds.), The social psychology of HIV infection, Hillsdale, New Jersey; y Hove y Londres, Lawrence Erlbaum, 85-123.

Mindreau, N. \& Morales, C. (1996). Diferencias en las actitudes hacia la sexualidad en relación a la socialización religiosa. Una comparación entre católicos, judíos y agnósticos. En III Coloquio de Estudiantes de Psicología (Interuniversitario). Lima: Pontificia Universidad Católica del Perú, 209-234.

Montoya, R. (1998). Multiculturalidad y política. Derechos indígenas, ciudadanos y humanos. Lima: Sur.

Munder Ross, J. (1979). The forgotten father. En: Coleman Nelson, M. \& Ikenberry, J. (Eds.), Psychosexual imperatives. Their role in identity forma- 
tion. New York: Human Sciences Press, 261-303.

Nipperdey, Th. (1993). Deutsche Geschichte 1866-1918 (vol. 1: Arbeitswelt und Buergergeist). Munich: C.H. Beck.

Nitzschke, B. (1982). Die Bedeutung der Sexualitaet im Werk Sigmund Freuds. En Eicke, D. (Ed.), Tiefenpsychologie (vol. 1: Sigmund Freud-Leben und Werk), Weinheim y Basilea, Beltz, 357-396.

Nozick, R. (1992). Meditaciones sobre la vida. Barcelona: Gedisa.

Ott, U. (1999) Liebe Suende. Die Woche, edición del 8 de enero, p. 25.

Palomino C.H. (1998). Creencias y opiniones acerca del daño en estudiantes universitarios de Lima y Chiclayo. Lima: Universidad Ricardo Palma, Facultad de Psicología, tesis para optar el título de licenciado en psicología.

Peterson, J.L. \& Marín, G. (1988). Issues in the prevention of Aids among black and hispanic men. American Psychologist, 43, 871-877.

Ponce, A. \& La Rosa, L. (1995). Nuestra sexualidad. Mis abuelos, mis padres $y$ yo. Construcciones sociales de la sexualidad en tres grupos generacionales. Lima: Pontificia Universidad Católica del Perú.

Prado, J. (1941). Estado social del Perú. Durante la dominación española (Estudio histórico-sociológico). Lima: Librería e Imprenta Gil.

Richardson, D. (1990). La mujer y el SIDA. México, D.F.: El Moderno.

Rivera-Mosquera, E.T. \& Dowd, E.Th. (1999). Temas y consideraciones éticas al trabajo con pacientes gays y les- bianas. Revista Argentina de Clínica Psicológica, 8, 5-14.

Routh, D.K. (1998). Hippocrates meets Democritus: a history of psychiatry and clinical psychology. En Bellack, A.S. \& Hersen, M. (Eds.), Comprehensive Clinical Psychology (vol. 1, Foundations, ed. por C.E. Walker), Amsterdam, Elsevier, 7-48.

Ruíz-Bravo, P. (1996). Un balance de los estudios de género en el Perú. En RuízBravo, P. (Ed.), Detrás de la puerta. Hombres y mujeres en el Perú de hoy, Lima: Pontificia Universidad Católica del Perú, 5-26.

Salaverry, O.M. \& Gonzales, G.F. (1994). Factores psicosociales asociados al embarazo en adolescentes de las ciudades de Lima, Cusco y Pucallpa. En Gonzales, G.F., (Ed.), La adolescencia en el Perú. Lima: Universidad Peruana Cayetano Heredia, 199-258.

Sanders, K. (1997). Nación y tradición. Cinco discursos en torno a la nación peruana. Lima: Pontificia Universidad Católica del Perú y Fondo de Cultura Económica.

Schaffer, K.F. (1981). Sex roles and human behavior. Cambridge: Mass.: Winthrop.

Schofield, M. (1968). The sexual behaviour of young people. Harmondsworth: Penguin.

Sears, R.R. (1984). Tipificación sexual, elección del objeto y crianza del niño. En Katchadourian, H.A. (Comp.), La sexualidad humana. Un estudio comparativo de su evolución. México, D.F.: Fondo de Cultura Económica, 241-262.

Silvestre, N., Solé, M.R., Pérez, M. \& Jodar, M. (1996). Psicología evolutiva. 
Adolescencia, edad adulta y vejez. Barcelona: CEAC.

Smith, E.R. \& Mackie, D.M. (1997). Psicología social. Madrid: Panamericana.

Sontag, S. (1996). La enfermedad y sus metáforas y el sida y sus metáforas. Madrid: Taurus.

Soto Cáceres, V. (1972). Comportamiento sexual del universitario peruano. Quince años de investigación científica. Lima: Concytec.

Stevens, E.P. (1997). Marianismo: la otra cara del machismo en Latinoamérica. En Pescatello, A. (Comp.), Hembra y macho en Latinoamérica. Ensayos. México, D.F.: Diana, 121-134.

Textor, M.R. (1991). Familien: Soziologie, Psychologie. Eine Einfuehrung. Freiburg im Breisgau: Lambertus.

Valdez, H., Adachi, R. \& Gotuzzo, E. (1991). Prácticas sexuales en la población universitaria de Lima. Análisis de los factores de riesgo para la transmisión sexual del virus de la inmunodeficiencia humana. Revista Médica Herediana, 2, 18-23.

Van der Pligt, J., Otten, W., Richard, R. \& Van der Velde, F. (1993). Perceived risk of AIDS: unrealistic optimism and selfprotective action. En Pryor, J.B. \& Reeder, G.D. (Eds.), The social psychology of HIV infection, Hillsdale, New Jersey; y Hove y Londres: Lawrence Erlbaum, 39-58.

Van Landingham, M., Grandjean, N., Suprasert, S. \& Sittritai, W. (1997). Dimensions of Aids knowledge and risky sexual practices: a study of northern Thai males. Archives of Sexual Behavior, 26, 269-293.
Walsh, A. (1991). Self-esteem and sexual behavior: exploring gender differences. Sex Roles, 25, 441-450.

Wang, J., Fisher, J.H. \& Chen, J. (1995). Population growth and population control. En Magill, F., (Ed.), International Encyclopedia of Sociology (vol. 2). Londres, Chicago: Fitzroy Deaborn Pub., 972-976.

Wilbur, M.P. (1994). AIDS and sexual behavior. En Ramachandran, V.S. (Ed. en jefe), Encyclopedia of human behavior, (vol. 1). San Diego: Academic Press, 81-92.

Wilson, G.D. (1978). The secrets of sexual fantasy. Londres: Dent.

Wilson, G.D. (1989). The great sex divide. Londres: Peter Owen.

Wilson, G.D. (1997). Sex and personality. En Nyborg, H., (Ed.), The scientific study of human nature: tribute to Hans J. Eysenck at eighty. Londres: Pergamon Press, 165-188.

Yanaylle García, M.E. (1996). Tiene veintiocho años y aún es virgen. Femineidad y estereotipo de la mujer sin pareja. En Ruiz-Bravo, P. (Ed.), Detrás de la puerta. Hombres y mujeres en el Perú de hoy. Lima: Pontificia Universidad Católica del Perú, 73-90.

Yon Leau, C. (1996). Qué cosa es ser hombre. ¿Crisis de la modernidad? Quehacer, 101, 77-90.

Zuckerman, M., Tushup, R. \& Finner, S. (1976). Sexual attitudes and experiences: attitude and personality correlates and changes produced by a course in sexuality. Journal of Consulting and Clinical Psychology, 44, 7-19. 